\title{
On the importance of appropriate precipitation gauge catch correction for hydrological modelling at mid to high latitudes
}

\author{
S. Stisen, A. L. Højberg, L. Troldborg, J. C. Refsgaard, B. S. B. Christensen, M. Olsen, and H. J. Henriksen \\ Geological Survey of Denmark and Greenland - GEUS, Øster Voldgade 10, 1350 Copenhagen, Denmark
}

Correspondence to: S. Stisen (sst@geus.dk)

Received: 2 March 2012 - Published in Hydrol. Earth Syst. Sci. Discuss.: 16 March 2012

Revised: 9 August 2012 - Accepted: 1 September 2012 - Published: 12 November 2012

\begin{abstract}
Precipitation gauge catch correction is often given very little attention in hydrological modelling compared to model parameter calibration. This is critical because significant precipitation biases often make the calibration exercise pointless, especially when supposedly physically-based models are in play. This study addresses the general importance of appropriate precipitation catch correction through a detailed modelling exercise. An existing precipitation gauge catch correction method addressing solid and liquid precipitation is applied, both as national mean monthly correction factors based on a historic $30 \mathrm{yr}$ record and as gridded daily correction factors based on local daily observations of wind speed and temperature. The two methods, named the historic mean monthly (HMM) and the time-space variable (TSV) correction, resulted in different winter precipitation rates for the period 1990-2010. The resulting precipitation datasets were evaluated through the comprehensive Danish National Water Resources model (DK-Model), revealing major differences in both model performance and optimised model parameter sets. Simulated stream discharge is improved significantly when introducing the TSV correction, whereas the simulated hydraulic heads and multi-annual water balances performed similarly due to recalibration adjusting model parameters to compensate for input biases. The resulting optimised model parameters are much more physically plausible for the model based on the TSV correction of precipitation. A proxy-basin test where calibrated DK-Model parameters were transferred to another region without site specific calibration showed better performance for parameter values based on the TSV correction. Similarly, the performances of the TSV correction method were superior when considering two single years with a much dryer and a much wetter winter, respectively, as compared to the winters in the
\end{abstract}

calibration period (differential split-sample tests). We conclude that TSV precipitation correction should be carried out for studies requiring a sound dynamic description of hydrological processes, and it is of particular importance when using hydrological models to make predictions for future climates when the snow/rain composition will differ from the past climate. This conclusion is expected to be applicable for mid to high latitudes, especially in coastal climates where winter precipitation types (solid/liquid) fluctuate significantly, causing climatological mean correction factors to be inadequate.

\section{Introduction}

Precipitation is inevitably a crucial variable in any water resources assessment. Without accurate measurements or estimates of precipitation, water balance studies and modelling becomes meaningless (Larson and Peck, 1974).

Numerous studies have investigated the impact of precipitation data quality on hydrological model predictions. Some have focussed on gauge network density (Bardossy and Das, 2008), precipitation algorithms (Gourley and Vieux, 2005 ) and the issues of precipitation uncertainty (Kampf and Burges, 2010; Kavetski et al., 2006; Looper et al., 2012; McMillan et al., 2011). It is however clear that precipitation input errors should always be minimized and corrected prior to model calibration (Leimer et al., 2011). Mizukami and Smith (2012) analysed the effect of inconsistencies in multiannual precipitation records through a modelling exercise, but focussed on gauge relocation and changes in data processing, not on changes caused by actual climatic variations, which could affect the precipitation correction. Andréassian

Published by Copernicus Publications on behalf of the European Geosciences Union. 
et al. (2001) and later Oudin et al. (2006) evaluated the impact of bias and random error in climate input on both optimised model parameters and model performance and found large impacts of systematic precipitation bias. Whey also concluded that the impact of biases could be reduced if the model structure allowed the model parameters to adapt to water balance closure through calibration.

Issues of appropriate correction of precipitation in time and space and the implications for large scale water resources modelling are the topic of the current study. The recent focus on water resources impact assessment related to climatic change is usually based on hydrological models which are calibrated and validated for the current climate and subsequently utilized for predictions under different future climatic conditions. This approach is highly dependant on the validity of the model parameterisation obtained under current conditions, and will not be suitable if the model based on current climate is tuned to compensate for biases in precipitation input.

For individual precipitation gauges, systematic biases can be caused by catch deficiencies, mainly the wind-induced undercatch of solid precipitation (Adam and Lettenmaier, 2003; Nespor and Sevruk, 1999). At mid to high latitudes $\left(45-65^{\circ}\right)$, systematic biases in solid (winter) precipitation will have a significant effect on the assessment of water balances at all temporal and spatial scales, even when biases are relatively small, because most groundwater recharge and stream flow occur in winter and spring when evapotranspiration rates are low.

Detailed catch correction methods exist (Allerup et al., 1997; Goodison et al., 1998; Groisman and Legates, 1995; Nespor and Sevruk, 1999; Sevruk and Nespor, 1998) and they have been applied in several studies (Forland and Hanssen-Bauer, 2000; Fortin et al., 2008; Yang et al., 2005), revealing large differences between the correction of solid and liquid precipitation. Comprehensive studies of precipitation undercatch have been conducted at the global scale on gridded datasets of $0.5^{\circ}$ to $2.5^{\circ}$ based on mean monthly correction factors (Adam and Lettenmaier, 2003; Huffman et al., 1997; Legates, 1995). Other studies have examined the effect of catch correction on continental scale runoff using coarse modelling schemes (Adam et al., 2007; Berezovskaya et al., 2004; Fekete et al., 2004; Tian et al., 2007; Voisin et al., 2008). Valéry et al. (2009) attempted to utilized stream flow measurements as catchment water balance data to calibrate the snow undercatch correction of mountainous catchments through simple water balance models.

Few detailed water balance studies at the catchment to national scale are specific about the precipitation gauge catch correction method applied (see Bowling et al. (2003) and Stisen et al. (2011a) for exceptions). This is the case even for applications in regions where solid precipitation is significant and where precipitation biases can easily amount to 20 $40 \%$ during winter months. Unfortunately, the lacking focus on catch correction is probably mainly due to the fact that many hydrological models are evaluated against discharge data only and that model parameter optimisation can compensate for precipitation biases, and not because such biases are negligible.

The issue of appropriate precipitation gauge catch correction is especially relevant in transitional climates and seasons where both solid and liquid precipitation occur (Adam and Lettenmaier, 2003). These transitional climates are common at mid to high latitudes $\left(45-65^{\circ}\right)$ and in coastal climate zones where winter temperatures and thereby precipitation types vary considerably both from day to day and year to year. Under such conditions a standard climatology of mean monthly correction factors is not ideal for describing the bias caused by wind-induced undercatch of solid precipitation. Instead a temporally and spatially dynamic precipitation gauge catch correction has to be applied taking into account the actual wind speed and precipitation type during each observation. Transient climatic conditions with both solid and liquid precipitation can also be found at high elevations and in mountainous terrain, where similar precipitation correction issues are found. This is however not analysed in the current study.

Evaluation of different precipitation dataset and bias correction methods can be done through hydrological modelling. However, this requires a physically-based approach where both model performance and optimised parameters are considered. Ideally, the model should be evaluated against runoff, groundwater levels and actual evapotranspiration; however, sufficiently accurate actual evapotranspiration estimates are generally not available at a regional to national scale.

The current study compares two different applications of the same catch corrections method (Allerup et al., 1997) to a national gridded precipitation gauge-based dataset for Denmark: (i) spatially uniform historic mean monthly (HMM) correction factors based on few climate stations with detailed observations (1961-1990), and (ii) time-space variable (TSV) correction factors based on current and local wind speed and temperature. Subsequently, the national Danish water resources model, a comprehensive coupled surfacesubsurface model, is calibrated separately with both precipitation dataset. Finally, the two correction methods are compared in terms of calibration and validation performances and evaluation of model parameters and state variables not included in the calibration. Precipitation correction has previously been evaluated for a single catchment in Denmark (Stisen et al., 2011b). The current study broadens the findings of that study by including the spatial dimension in the TSV correction and by applying the two methods to a much wider range of climatic and hydrogeological regions. The large differences in precipitation pattern and hydrological responds between West and East Denmark combined with the multiple model domains, make the results generic to regions where solid precipitation is significant and where modellers therefore face the issues of appropriate precipitation catch correction. 


\section{Precipitation gauge catch-correction}

This section describes the standard methodology for precipitation correction of the Danish Hellmann precipitation gauge. Even though the method is essentially empirical, the main elements of the correction model are identical to any other correction model since underestimation of precipitation is mainly a function of precipitation type, wind speed and shielding conditions (Larson and Peck, 1974). This implies that even though other institutions or agencies in other regions might have different correction models, the consequences of insufficient use of these models can be assumed similar to the findings of this study.

The Danish precipitation gauge network has, up until 2010 , consisted mainly of manual stations equipped with the Hellmann precipitation gauge. The placement of the gauge at $1.5 \mathrm{~m}$ above ground is the primary cause of wind-induced undercatch due to the turbulence around the opening of the gauge. Wetting losses and evaporation from the gauge contribute to the underestimation of precipitation, but by far the most important error source is the wind-induced undercatch, especially for solid precipitation. In 1972 a study on precipitation correction was initiated in Denmark, which resulted in a correction method for liquid precipitation (Allerup and Madsen, 1980). Based on a WMO initiative from 1985 (Goodison et al., 1998), "The Solid Precipitation Intercomparison Project" was carried out during the period 19871998. The project included several countries who established national and regional test fields equipped with the Double Fence International Reference (DFIR) for solid precipitation. The goals of the project were to determine systematic biases in measurements of solid precipitation, derive methods for correction of solid precipitation and to introduce a reference method for solid precipitation measurement. The Nordic test facility was established in Jokionen, Finland (1987-1993). Based on data from the Finnish test site, the correction method for liquid precipitation (Allerup and Madsen, 1980) was extended to include mixed and solid precipitation (Allerup et al., 1997). The elegancy of the method is its ability to handle all precipitation types in one expression through the unifying snow fraction parameter $\alpha$, which is considered a function of temperature (see details on $\alpha$ in Sect. 2.2).

$C(\alpha)=\alpha \cdot C_{\text {solid }}(V, T)+(1-\alpha) \cdot C_{\text {liquid }}(V, I)$.

$C(\alpha)$ is the combined correction factor for any combination of solid and liquid precipitation. Correction for liquid precipitation is a function of wind speed and precipitation intensity, while wind speed and temperature are used in the correction of solid precipitation.

$$
\begin{aligned}
& C_{\text {liquid }}=\exp \left\{0.007697+0.034331 \lambda_{\text {liquid }} u\right. \\
& \left.\quad+(-0.00101 \ln (I))+\left(-0.012177 \lambda_{\text {liquid }} u \ln (I)\right)\right\} \\
& C_{\text {solid }}=\exp \left\{0.04587+0.23677 \lambda_{\text {solid }} u\right. \\
& \left.\quad+0.017979 T+\left(-0.015407 \lambda_{\text {solid }} u T\right)\right\},
\end{aligned}
$$

where $C_{\text {liquid }}$ and $C_{\text {solid }}$ are the correction factors for liquid and solid precipitation, respectively $[-], \lambda_{\text {liquid }}$ and $\lambda_{\text {solid }}$ are the wind corrections $[-], u$ is the wind speed at reference height $(1.5 \mathrm{~m})\left[\mathrm{m} \mathrm{s}^{-1}\right], I$ is precipitation intensity $[-]$ and $T$ is air temperature $\left[{ }^{\circ} \mathrm{C}\right]$. All variables are assumed to be measured during precipitation and the empirical constants only apply to the unshielded Danish Hellmann precipitation gauge.

Since the method has not been validated at extreme wind speeds, a threshold of $15 \mathrm{~m} \mathrm{~s}^{-1}$ and $7 \mathrm{~m} \mathrm{~s}^{-1}$ is applied for liquid and solid precipitation, respectively. In case of observed wind speeds above these values, wind speed is set to the threshold value.

\subsection{Historic mean monthly correction factors 1961-1990}

The Allerup model is applied by the Danish Meteorological Institute (DMI) to calculate mean monthly standard correction factors for each $30 \mathrm{yr}$ climatology period. The current correction factors are based on the period 1961-1990, and are national average factors for three shelter categories, A, B and C (Allerup et al., 1998). These factors are estimated using data from a relatively sparse network of 12 stations nationwide where all required input are available. As indicated above, the required input includes wind speed, temperature, precipitation type and intensity, all measured during precipitation at the same location as the precipitation gauge. Until recently the Danish recommendations for hydrological applications were to use the mean monthly standard correction factors (Plauborg et al., 2002), either for individual precipitation gauges with known shelter category or applied to the national $10 \mathrm{~km}$ grid dataset (Scharling, 1998) using the average shelter category $\mathrm{B}$, as done in this study. This correction method is referred to as the historic mean monthly (HMM) correction method.

\subsection{Time-space variable correction factors}

As an alternative to the historic mean monthly correction factors, the Allerup model has been applied in a dynamic mode using daily wind speed and temperature data to estimate individual correction factors for each grid for each day, referred to as the time-space variable (TSV) correction method. In order to perform such a precipitation gauge catch correction, a number of simplifications have to be made since the required input for the correction model are not available at the optimal temporal and spatial resolution. The impact of such simplifications has previously been justified by Allerup et al. (2000) where precipitation correction based on off-site weather information was investigated in detail. They concluded that data obtained within a distance of $50 \mathrm{~km}$ from the gauge would provide suitable information for applying the correction model. Regarding the temporal resolution in the current study, precipitation is recorded as daily sums, with no 
information on the time or duration of precipitation events. Likewise, the wind speed and air temperature is applied as daily average values. This corresponds to the temporal resolution of the precipitation data, but might result in errors, especially if temperatures fluctuate around the freezing point where the distinction between liquid and solid precipitation switches or if wind speeds are highly different during and outside a precipitation event. In order to compensate partly for the missing information on precipitation duration, the precipitation intensity $(I)$ is applied as monthly mean values, which will address the seasonal variability of typical intensities but not the correct intensity on a given day. As given by Eq. (3), intensity only appears in the estimation of the correction factor for liquid precipitation, which in general is much smaller than the correction factor for solid precipitation and thereby less significant for the total water budget. Regarding the spatial resolution of wind speed and temperature, the data applied in the correction model is the national $20 \mathrm{~km}$ grid, which matches the $10 \mathrm{~km}$ precipitation grid but is based on a sparser network of stations.

The correction applied here is performed on the national $10 \mathrm{~km}$ grid dataset. Below, the different simplifications are summarized.

- The corrections are estimated and applied to daily mean precipitation amounts not accounting for the actual conditions during precipitation.

- Precipitation intensity and wetting loss are assigned as mean monthly values (Vejen, 2005).

- Wind speed and temperature are mean daily values taken from the national $20 \mathrm{~km}$ grid (Scharling, 1999).

- Wind speed is downscaled to precipitation gauge measurement height $(1.5 \mathrm{~m})$, assuming a logarithmic wind profile and a uniform surface roughness of $0.25 \mathrm{~m}$.

- No consideration is made to actual station shelter conditions; average conditions are assumed for the $10 \mathrm{~km}$ grid data. According to Allerup et al. (1998), average shelter conditions result in $\lambda_{\text {liquid }}=0.78$ and $\lambda_{\text {solid }}=0.70$.

- Discrimination between liquid and solid precipitation is performed based on temperature. Liquid $>2{ }^{\circ} \mathrm{C}(\alpha=0)$, solid $<0^{\circ} \mathrm{C}(\alpha=1)$, and mixed precipitation is between 0 and $2{ }^{\circ} \mathrm{C}(\alpha=1-0.5 \cdot T)$, following Vejen (2005).

Following these simplifications, the TSV correction is performed on each of the 609 grids for each day during 19902010. Similar simplifications have been applied by Vejen (2005) to an island of Denmark. In a recent study by Refsgaard et al. (2011), an attempt was made to evaluate the TSV correction against the HMM correction for a common reference period, although based on sparse data, this analysis indicated no sign of a systematic bias when applying the simplifications of the TSV correction method. In addition, an analysis of the effect of correcting gridded precipitation data compared to correcting point precipitation gauge data (and subsequently interpolating to grids) was carried out for two sub domains of Denmark (Refsgaard et al., 2011). The main differences between these two datasets are in the individual precipitation gauge shelter conditions for the gauge based correction. The analysis did however reveal that, both regarding the spatio-temporal precipitation pattern and hydrological modelling optimisation and performance, differences between the two approaches were insignificant.

\subsection{Differences between HMM and TSV corrections}

The main advantage of the mean monthly correction factors is the ease of use, especially for operational large scale applications. Also, they are assumed more robust as national average factors for the period(s) they cover since they can be estimated using detailed observations without assumptions on the suitability of off-site information. However, there are several limitations, such as the lack of spatial information, inability to differentiate warm and cold winters and short term variability in precipitation type. In addition, they are not particularly suited to applications outside the period they are calculated for, since even longer term climate trends are neglected. It is known, e.g. for the Danish case, that the winters in the recent period 1990-2010 have been significantly warmer than the reference period 1961-1990, resulting in fewer solid precipitation events and therefore lower correction factors (Refsgaard et al., 2011).

Figure 1 illustrates the spatial distribution of mean precipitation over Denmark for the period 1990-2010 when applying the HMM and TSV correction methods to the $10 \mathrm{~km}$ grid dataset. Even though the annual differences are relatively small, on the order of 3-6\%, the difference has a seasonal bias that changes the seasonal pattern of precipitation between summer and winter. As indicated in Fig. 1b, the difference between the two correction methods is almost exclusively found in the winter months (December, January and February), where differences of up to $14 \%$ are found, whereas the annual differences are lower, with maximum values of around $7 \%$. As expected, the TSV correction generally has lower precipitation amounts due to the on average warmer winters of the period 1990-2010 compared to the period 1961-1990, resulting in lower winter correction factors. In addition, there is a clear spatial pattern in the difference between the corrected precipitation datasets, where differences are largest in South-West Denmark. This highlights the limitations of the HMM correction, which is applied as national average values with not consideration to regional differences. 

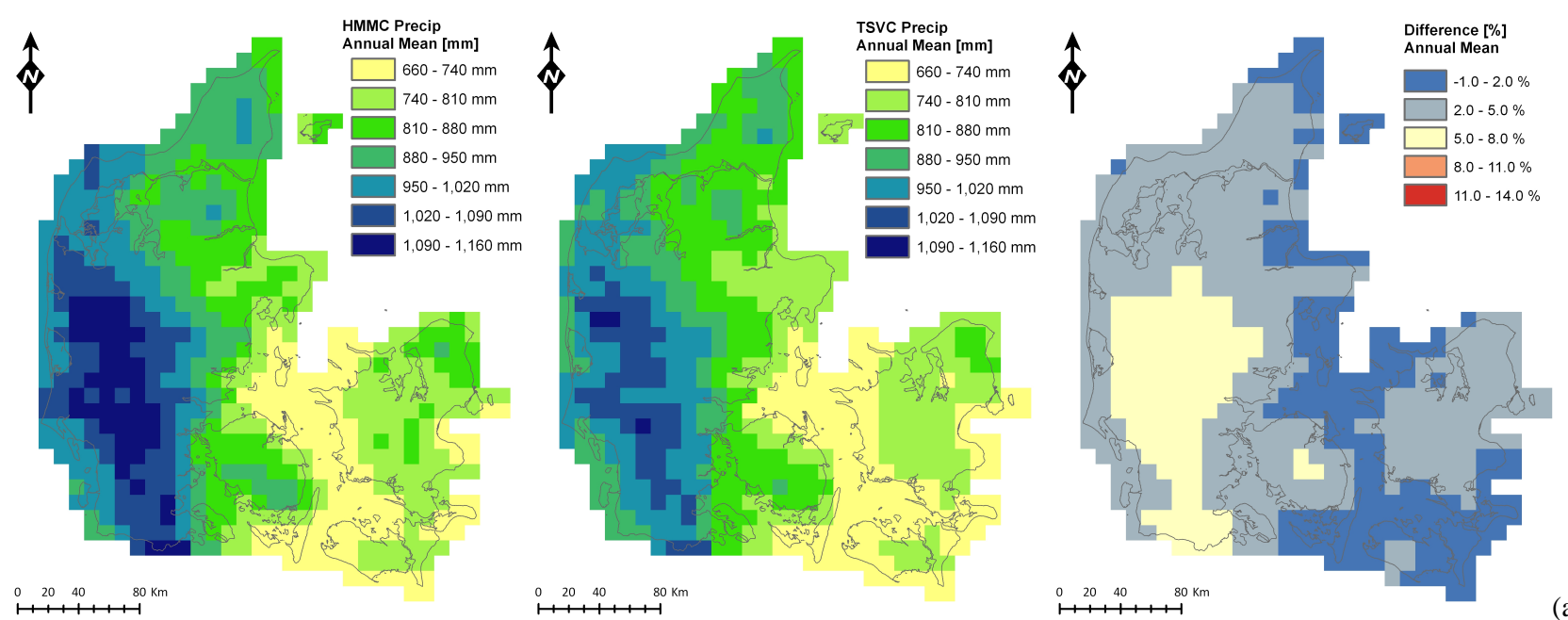

(a)
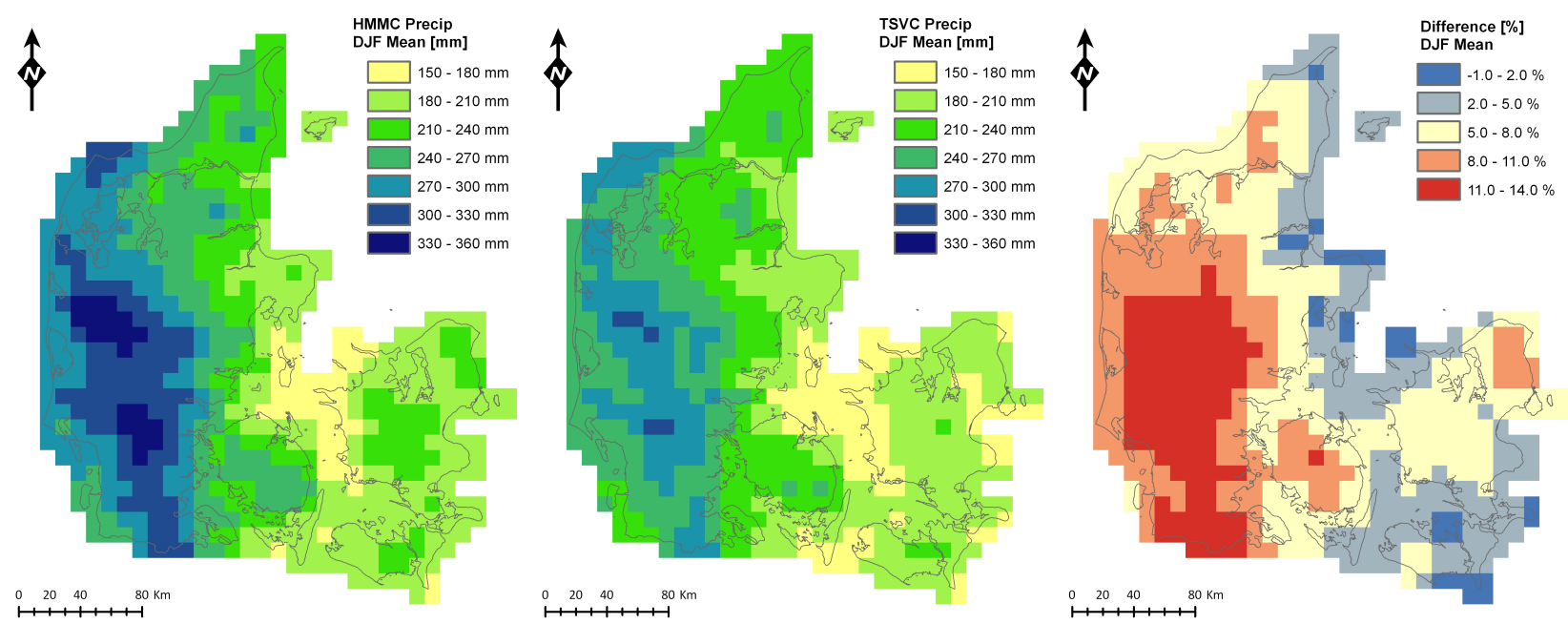

(b)

Fig. 1. Spatial distribution of mean annual precipitation (a) and winter precipitation (DJF) (b) for Denmark with HMM and TSV precipitation correction.

\section{The coupled surface-subsurface model}

The groundwater-surface water modelling presented here is based on the National Water Resources Model (the DKmodel) developed at the Geological Survey of Denmark and Greenland. The National model was initiated in 1996 and the first version was released in 2001 (Henriksen et al., 2003). During the period 2005-2009, the model went through a major update including a new enhanced interpretation of the national hydrogeological model based on new groundwater mapping data from geophysical mapping and subsequent modelling at smaller scale, providing local and regional geological model updates of the first DK-model geology (in a $100 \times 100 \mathrm{~m}$ resolution for the geological model). In addition, the hydrological model resolution was reduced from $1000 \mathrm{~m}$ to $500 \mathrm{~m}$, and the unsaturated zone module was dynamically coupled to both the irrigation module and the saturated zone modules (Højberg et al., 2012). All simulations are done using self-adjusting time stepping with a maximum time step of 24 hours.

The national water resources model is split into seven regional models (Højberg et al., 2012) for reasons of computational efficiency. For the domains not consisting of islands (domains 4, 5 and 6, Fig. 2), the land phase boundary conditions are delineated from the topography. Of the seven model domains, six are included in this study (Fig. 2), excluding the Island of Bornholm $\left(590 \mathrm{~km}^{2}\right)$ in the Baltic Sea. The six model domains cover $42087 \mathrm{~km}^{2}$ or approximately $98 \%$ of Denmark.

\subsection{Model code}

The MIKE SHE modelling system is the hydrological modelling tool of the National Water Resources Model. MIKE SHE is a physically-based, distributed modelling system covering the entire land phase of the hydrological cycle 


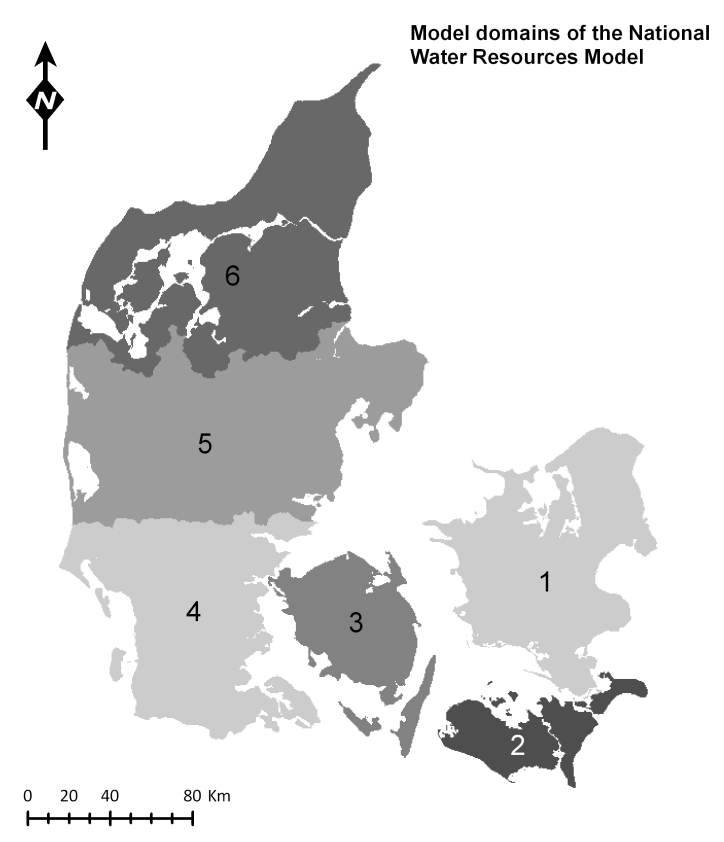

Fig. 2. Six model domains of the Danish national water resources model.

(Abbott et al., 1986; Graham and Butts, 2005). This code was selected due the comprehensive description of groundwatersurface water interactions and the ability to include various unsaturated zone and evapotranspiration formulations. The current model setup is based on a full 3-D finite difference groundwater module coupled with a simplified twolayer unsaturated zone module (Yan and Smith, 1994). The river routing is done using the MIKE 11 code, integrated into MIKE SHE, applying the kinematic routing method.

The MIKE SHE/MIKE 11 modelling system can be considered a coupled surface-subsurface model. In contrast to the more sophisticated, truly integrated models such as ParFlow (Kollet and Maxwell, 2006) and HydroGeoSphere (Therrien et al., 2005) which solve the subsurface variably saturated equations by applying a 3-D Richards equation, MIKE SHE solves the saturated, unsaturated and river flow in separate modules that are coupled two-ways in every time step. The coupled models are computationally much more efficient, which enables comprehensive inverse modelling even for simulation of large areas like the one applied in the current study. The issues related to calibration of distributed physically-based hydrological models have been discussed extensively (Beven, 2001, 2007; Refsgaard, 1997, 2000). While it can be argued that physically-based models should not be calibrated at all, the parameter optimisation employed in the current study is based on a parsimonious approach where a relatively high degree of spatial and temporal variability in model input are combined with a limited number of free parameters by tying parameters together and maintaining initial spatial patterns of parameters. While such an approach will inevitably result in some degree of effective

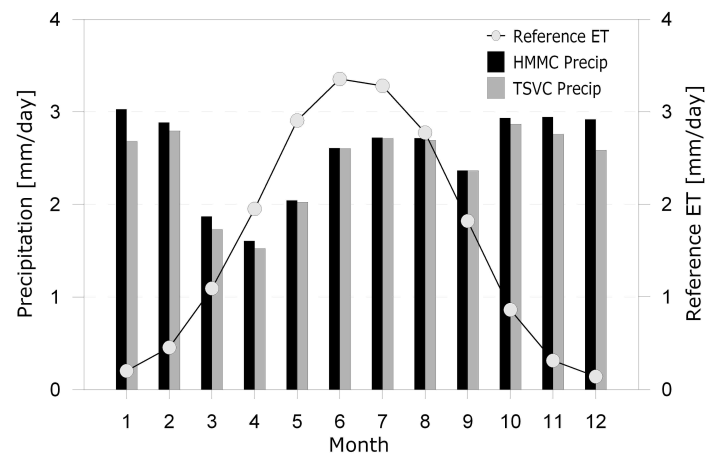

Fig. 3. Monthly average precipitation and reference ET rates for Denmark for the period 2000-2007. Precipitation rates are given for both the HMM and TSV precipitation corrected.

parameterisation, we argue that the optimised parameter values can still be interpreted as physical and give indications of model structural errors or input biases.

\subsection{Model input and climate forcing data}

\subsubsection{Climate data}

Precipitation data are based on the daily national $10 \mathrm{~km}$ grid dataset provided by the DMI. The precipitation has been corrected for undercatch according to the two methods described above, HMM and TSV. Regarding reference evapotranspiration $\left(\mathrm{ET}_{\text {ref }}\right)$ and temperature data, the daily $20 \mathrm{~km}$ national grid dataset produced by the DMI is used. $\mathrm{ET}_{\text {ref }}$ is calculated using the Makkink equation adjusted for conditions in East Denmark (Scharling, 1999). According to current recommendations (Refsgaard et al., 2011), the $\mathrm{ET}_{\text {ref }}$ has been reduced to $95 \%$ of the original values for West Denmark (model domains 3, 4, 5 and 6, Fig. 2). This is done to compensate for a documented overestimation of the Makkink equation compares to the Penman-Montieth equation for West Denmark (Detlefsen and Plauborg, 2001). All meteorological time series are available for the period 19902010. As indicated in Fig. 3, precipitation in Denmark is fairly evenly distributed over the year. In contrast, reference ET has a strong seasonal cycle with very low values in winter, resulting in a distinct seasonal pattern in groundwater recharge rates with low values in summer and high in winter.

\subsubsection{Geological models and soil data}

The geological model was developed during the recent update of the National Water Resources Model (Højberg et al., 2012) and can roughly be divided into two geographical regions: one covering the peninsula of Jylland (Model domains 4, 5 and 6 in Fig. 2); and one covering the Islands of Fyn, Sjælland, Falster and Lolland, in addition to some smaller Islands (model domains 1, 2 and 3 in Fig. 2). The conceptual hydrogeological models for model domain 1 , 
2 and 3 includes a Quaternary sequence conceptualised as moraine clay with sand lenses embedded in three and four vertical levels for sub-model 3 and sub-models 1 and 2, respectively. Surface-near geology was adopted from the Danish soil map (http://www.geus.dk) and assumed to represent the geology to a depth of three meters below the surface. The pre-Quaternary deposits are predominantly Danien limestone, but also include Paleocene marl with low permeability in sub-model 3 and the western part of sub-models 1 and 2 (Højbjerg et al., 2012). The geological model for Jylland (model domains 4, 5 and 6) consists of a pixel based geological model overlaid by a number of geological lenses. Five different hydro-facies are used to describe the subsurface: The Quaternary is divided into a binary system of sand and clay; whereas three pre-Quaternary units - quartz sand, Miocene mica sand, and clay - are used. The geological lenses correspond to the division of the computational layers used in the numerical groundwater model. Depending on the complexity of the regional geology, each model domain thus has a different number of computational layers (Højberg et al., 2012).

Soil data are distributed according to the Danish soil type classification consisting of 11 classes in three horizons (AC). The classes named JB1-JB10 range from coarse sand to compact clay, while the last soil class JB11 represents organic soils. For each class and model domain, average values for field capacity, wilting point and saturated water content are estimated from gridded soil property maps containing the soil physical attributes in $500 \mathrm{~m}$ resolution (Børgesen and Schaap, 2005; Greve et al., 2007). Since the two-layer unsaturated zone model in MIKE SHE only considers average root zone conditions, soil physical properties from horizon B are used.

\subsubsection{Land use and vegetation data}

Land use is divided into the 21 classes listed in Table 1. Agricultural farmland is, in addition to the crop types, subdivided according to soil type. This is done because maximum rooting depth for agricultural crops, which is an important water balance parameter, is largely controlled by soil type. Forest is divided into deciduous and coniferous forests, with the first dominating in East Denmark and the latter in West Denmark. Remaining land cover types such as urban and sparsely vegetated areas are included but considered of minimal importance for the national water balance. All land cover types are assigned annual leaf areas index (LAI) and root depth (RD) cycles that are repeated every year, implying that crop rotation is not considered. However, the distribution of each crop type is done in accordance with 2005 statistics for each regional county.
Table 1. Combination of vegetation and soil types defined in the DK-model.

\begin{tabular}{|c|c|c|c|c|}
\hline \multicolumn{2}{|c|}{ Land use } & \multirow{2}{*}{$\begin{array}{c}\begin{array}{c}\text { Maximum } \\
\text { root zone } \\
\text { depth }[\mathrm{m}]\end{array} \\
0.70\end{array}$} & \multirow{2}{*}{$\begin{array}{r}\begin{array}{r}\text { Coverage } \\
{\left[\mathrm{km}^{2}\right]}\end{array} \\
3009\end{array}$} & \multirow{2}{*}{$\begin{array}{c}\begin{array}{c}\text { Coverage } \\
{[\%]}\end{array} \\
7\end{array}$} \\
\hline Permanent gr & & & & \\
\hline Forest, decidu & & 1.00 & 1855 & 4 \\
\hline Forest, conife & & 0.85 & 3410 & 8 \\
\hline Heath/sparse & egetation & 0.30 & 1024 & 2 \\
\hline Urbanised & & 0.10 & 3933 & 9 \\
\hline \multirow{4}{*}{$\begin{array}{l}\text { Farmland, } \\
\text { winter wheat }\end{array}$} & $\mathrm{JB} 1$ & 0.60 & 1346 & 3 \\
\hline & JB2 & 0.90 & 632 & 1 \\
\hline & JB3-JB4 & 1.20 & 2976 & 7 \\
\hline & JB5-JB10 & 1.50 & 6565 & 15 \\
\hline \multirow{4}{*}{$\begin{array}{l}\text { Farmland, } \\
\text { spring barley }\end{array}$} & JB1 & 0.60 & 1401 & 3 \\
\hline & JB2 & 0.80 & 494 & 1 \\
\hline & JB3-JB4 & 1.10 & 2324 & 5 \\
\hline & JB5-JB10 & 1.40 & 3781 & 9 \\
\hline \multirow{4}{*}{$\begin{array}{l}\text { Farmland, } \\
\text { grass }\end{array}$} & JB1 & 0.60 & 1328 & 3 \\
\hline & $\mathrm{JB} 2$ & 0.70 & 526 & 1 \\
\hline & JB3-JB4 & 0.80 & 2432 & 6 \\
\hline & JB5-JB10 & 0.90 & 3120 & 7 \\
\hline \multirow{4}{*}{$\begin{array}{l}\text { Farmland, } \\
\text { maize }\end{array}$} & JB1 & 0.60 & 491 & 1 \\
\hline & JB2 & 0.90 & 145 & 0 \\
\hline & JB3-JB4 & 1.20 & 770 & 2 \\
\hline & JB5-JB10 & 1.50 & 1194 & 3 \\
\hline
\end{tabular}

\subsubsection{Sinks and sources}

Within the coupled model a large number of abstractions and wastewater point sources are specified. In total, 40397 groundwater abstraction wells are included: 18551 for domestic and industrial use, and 21846 for irrigation. The groundwater abstractions for domestic and industrial use are specified by their location and filter depth as well as their annual abstraction. For the irrigation wells, an irrigation demand area surrounding each well is defined. The demand area prescribed for each well is a function of the density of wells and the fraction of land defined as agriculture within a buffer zone around each well. The actual irrigation amount is calculated internally in MIKE SHE from a demand function described by the root zone soil water deficit, and therefore varies according to climate, root depth and soil type. Since root depth is a calibration parameter affecting the total irrigation amount, the irrigation is simulated separately before the automatic calibration and applied as an additional precipitation. Volumes corresponding to the irrigation amount are extracted from the irrigation well beneath the irrigated grid cell. The decoupled procedure insures that the irrigation applied is identical for all model simulations independent of precipitation correction method and model parameter combination. The domestic abstractions are treated as an external sink which is removed from the model calculations. 
However, most of this is captured in the 1120 wastewater point sources. These external point sources are registered outlets from wastewater treatment plants corrected for rainwater contribution and are specified as discharge into the stream system.

\subsection{Calibration scheme}

The calibration framework is built around the PEST optimisation tool (Doherty, 2004), based on the Gauss-MarquardtLevenberg local search method. PEST is a non-linear estimator commonly used for optimisation of surface-groundwater models (Keating et al., 2003). The gradient based search methods are best suited for optimisations where the initial parameter set is relatively close to the optimal solution. This is assumed to be the case for the current version of the national water resources model, since it is a physically-based model where parameters have a physical meaning and can be estimated by other means than calibration. In addition, there is vast experience from previous calibrations of the National model, forming a good background for defining sound initial parameter values (Henriksen et al., 2003, 2008).

The model is run for the period 1990-2007, while simulations are evaluated for a calibration period (2000-2003) and a validation period (2004-2007). This ensures a ten-year warm up period, which is regarded as appropriate for the modelled hydrological system since initial conditions from the end of a previous model run are assigned. The winter precipitation (DJF), which mainly controls the discharge dynamics of individual years, is displayed in Fig. 4 for the calibration and validation periods. The figure reveals that the average winter precipitation is similar between the two periods, whereas the intra-annual variability is largest in the validation period.

Five of the six model domains included in this study are calibrated separately but following the same calibration protocol. The geology in model domains 1 and 2 are comparable, meaning model domain 2 has not been subject to calibration but used in a proxy-basin test where optimised parameters are transferred from model domain 1. A proxy-basin test can be used to test the robustness of the model conceptualisation, where an acceptable performance of domain 2 will indicate a sound model concept.

\subsubsection{Calibration parameters}

The model parameters included in the calibration process are selected based on sensitivity analyses, combined with consideration to parameter correlation. The calibration is performed separately for the five model domains, and the parameters selected vary slightly between the models due to differences in the dominating hydrogeological elements. The overall parameter groups are however identical, and cover hydrological properties of the subsurface, stream-aquifer interactions, drainage and the available water content for evapotranspiration. The stream-aquifer interaction and the

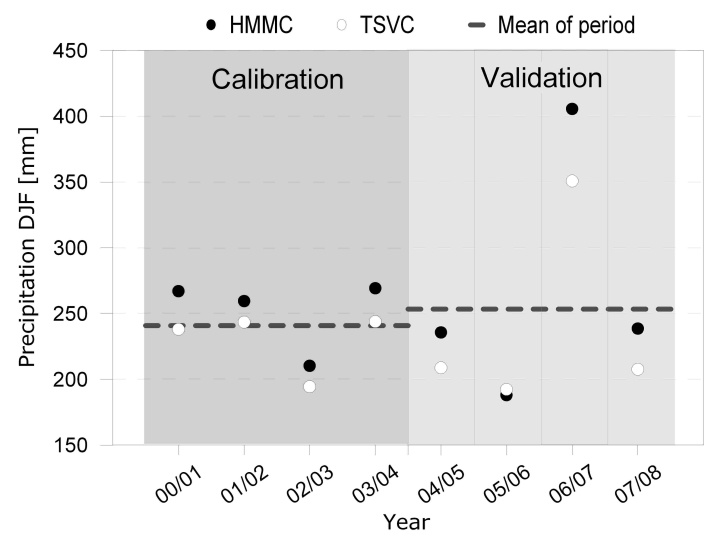

Fig. 4. Winter precipitation (DJF) for calibration and validation periods for the entire country.

drainage are represented by a single controlling parameter each, namely the leakage coefficient $\left[\mathrm{m} \mathrm{s}^{-1}\right]$ and the drainage time constant $\left[\mathrm{s}^{-1}\right]$, respectively. Based on a principle of parsimony, these two parameters are applied in a spatiallyuniform fashion. The available water content, which is the main control for the simulated actual evapotranspiration for a given potential ET, is a combination of several model parameters, such as the water content at field capacity and wilting point, the root depth, and the reduction function for plant water uptake at soil moisture contents below field capacity. The strategy for selecting the best optimisation parameter for controlling the simulated actual evapotranspiration has been to identify a parameter with large uncertainty but a high degree of physical meaning and to fix the other controlling parameters at physically-acceptable values centrally in their uncertainty span. Since soil physical properties are well described by distributed soil maps (Greve et al., 2007), these are fixed at their estimated values. The reduction of simulated evapotranspiration as a function of soil moisture content is controlled by a threshold value below which ET is reduced linearly and soil moisture reaches zero at the wilting point. The threshold is defined as a fraction of the field capacity, indicating that potential evapotranspiration occurs at moisture contents close to and above field capacity. Threshold values between 0.5 and 0.9 are physically realistic and consequently a value of 0.75 (Kristensen and Jensen, 1975) was selected after a sensitivity analysis indicated that this was a good value for average conditions. Similarly, the crop coefficients, which multiplied with ETref generate the ETpot, are also well defined with a relatively narrow acceptable range of uncertainty. Therefore, fixed values typically between 1.051.15 for summer conditions are applied for most vegetation types (Plauborg et al., 2002). Thereby, the rooting depth is the only free parameter controlling the simulated actual evapotranspiration in the calibration, implying that some of the uncertainty associated with other model parameters may be transferred to the root depth. 
Table 2. Calibration parameters, expected ranges are adapted from Henriksen et al. (2003).

\begin{tabular}{lllll}
\hline Parameter & Description & Used in Model domain & unit & Expected range \\
\hline Kx_Upper 3 $\mathrm{m}$ & Horizontal conductivity of the upper $3 \mathrm{~m}$ & 1 and 5 & $\mathrm{~m} \mathrm{~s}^{-1}$ & $1 \mathrm{e}-06-1 \mathrm{e}-04$ \\
Kx_Qsand & Horizontal conductivity of Quaternary sand & $1,3,4,5$ and 6 & $\mathrm{~m} \mathrm{~s}^{-1}$ & $1 \mathrm{e}-06-1 \mathrm{e}-02$ \\
Kz_Qclay & Vertical conductivity of Quaternary clay & $1,3,4,5$ and 6 & $\mathrm{~m} \mathrm{~s}^{-1}$ & $1 \mathrm{e}-11-1 \mathrm{e}-07$ \\
Kx_PQsand & Horizontal conductivity of Pre-Quaternary sand & 4,5 and 6 & $\mathrm{~m} \mathrm{~s}^{-1}$ & $1 \mathrm{e}-06-1 \mathrm{e}-02$ \\
Kz_PQclay & Vertical conductivity of Pre-Quaternary clay & $1,3,4,5$ and 6 & $\mathrm{~m} \mathrm{~s}^{-1}$ & $1 \mathrm{e}-11-1 \mathrm{e}-07$ \\
Kz_Chalk & Vertical conductivity of Chalk aquifer & 1,3 and 5 & $\mathrm{m} \mathrm{s}^{-1}$ & $1 \mathrm{e}-07-1 \mathrm{e}-03$ \\
Drain Time cons. & Drainage time constant & $1,3,4,5$ and 6 & $\mathrm{~s}^{-1}$ & $1 \mathrm{e}-08-1 \mathrm{e}-06$ \\
Leakage Coef. & River-aquifer leakage coefficient & $1,3,4,5$ and 6 & $\mathrm{~m} \mathrm{~s}^{-1}$ & $1 \mathrm{e}-10-1 \mathrm{e}-06$ \\
RD WW JB1 & Root depth of winter wheat for soil type JB1 & $1,3,4,5$ and 6 & $\mathrm{~m}$ & $0.4-0.8$ \\
\hline
\end{tabular}

Regarding the saturated zone parameters, these are selected as the directional hydraulic conductivities of the main 4-5 hydrogeological units of each model domain. Generally, horizontal conductivities $\left(K_{\mathrm{h}}\right)$ are selected for calibration in the aquifer units, whereas the vertical conductivities $\left(K_{\mathrm{V}}\right)$ are selected for the aquitard units. The anisotropy factor $\left(K_{\mathrm{h}} / K_{\mathrm{V}}\right)$ for the hydrological units is based on previous experiences in calibration of the national model and is generally 10 , which is not subject to calibration. The specific yield and specific storage of each hydrogeological unit are not included in the calibration, because experience has shown that with only limited detailed time series of hydraulic head fluctuations, physically realistic values of these parameters could not be obtained through automatic multi-objective calibration.

Typically, seven to eight free parameters are selected for each model domain, with several parameters tied to these free parameters. For the root depth, only the summer maximum root depth is subject to calibration because the winter root depth is very small for most land cover types and do not contribute to evapotranspiration because of the very low reference ET in winter. The maximum root depths for the 21 land use classes (Table 1) are all tied to a single root depth (arbitrarily chosen to be winter wheat for JB1). This means that, based on the initial values in Table 1 , the relation between all root depths are maintained through the calibration, and only one free root depth parameter is selected. The different parameter groups are listed in Table 2 along with their expected valid ranges. No parameter bounds have been put on any of the parameters during calibration based on the philosophy that, in case unrealistic parameter values are estimated, this is a valuable indication of conceptual model errors since only the most sensitive parameters are selected for calibration.

The initial model parameters are based on previous model optimisations except for the root depths in Table 1, which are based on Danish literature values (Refsgaard et al., 2011).

\subsubsection{Objective functions}

The model is designed for multiple purposes, which should reflect the calibration and validation process and the choice of objective functions (Højberg et al., 2012). Although the available calibration data are limited to stream discharge and hydraulic head observations, a multi objective calibration is pursued in order to increase the constraint on the model and evaluate it for different purposes. This means that in addition to the Nash Sutcliffe efficiency (NSE) (Nash and Sutcliffe, 1970) mainly describing the discharge dynamics, both the overall water balance error (WBE) and the water balance error in the low flow summer months $\left(\mathrm{WBE}_{\text {summer }}\right)$ are included as separate objective functions, because both the total water budget and the summer minimum flows are important for water managers. In order to exploit the data fully and constrain the model in accordance with the main modelling purposes, a set of objective functions are designed (Table 3). Observations of hydraulic head from wells are divided into three groups. One group is the monitoring wells where long, detailed time series are available. These observations are used to formulate the objective function $\mathrm{ME}_{\mathrm{HTS}}$, which is the mean simulation error for all observations in a given well, computed at a daily time step for the calibration period. The second group contains the wells where infrequent observations are available for the calibration period. These observations are compared to the closest simulated monthly value and represented as the mean of errors for a given well $\mathrm{ME}_{\mathrm{H}}$. The last group is wells where recent historic observations are available outside the calibration period only. The mean of observations for each well for the period 1990 2000 is compared to the simulated mean head for the period 2000-2003 ( $\left.\mathrm{ME}_{\mathrm{Hmean}}\right)$. This group of observations is included because they contribute to the spatial coverage of observations and because average hydraulic heads are not expected to change dramatically over time. Figure 5 shows the spatial distribution of observations of discharge and hydraulic head; note that for model domain 1 , only $\mathrm{ME}_{\mathrm{H}}$ are used because $\mathrm{ME}_{\mathrm{Hmean}}$ did not contribute significantly to the number of observations and coverage. In addition to the MEs 
Table 3. The eight objective functions are defined as follows:

\begin{tabular}{|c|c|c|c|}
\hline Objective function & $\begin{array}{r}\text { Stations/ } \\
\text { wells }\end{array}$ & $\begin{array}{c}\text { Relative } \\
\text { weight }\end{array}$ & Mainly sensitive to \\
\hline NSE: Nash-Sutcliffe model efficiency based on daily streamflow data [-] & 191 & 4.0 & $\begin{array}{l}\text { Root depth, drain } \\
\text { const., leak. coef. }\end{array}$ \\
\hline WBE: the total water balance error [\%] & 191 & 4.0 & Root depth \\
\hline $\mathrm{WBE}_{\text {summer: }}$ the water balance error for the low flow months June, July and August [\%] & 191 & 4.0 & $\begin{array}{l}\text { Root depth, } \\
\text { leak. coef. }\end{array}$ \\
\hline $\mathrm{ME}_{\mathrm{HTS}}$ : mean error of time series of hydraulic head [m] & 521 & 2.0 & K-values \\
\hline $\mathrm{ME}_{\mathrm{H}}$ : mean error of hydraulic head for a given well for the calibration period $2000-2003[\mathrm{~m}]$ & 8460 & 2.0 & K-values \\
\hline $\mathrm{ME}_{\text {Layers }}:$ mean hydraulic head error for each model layer for the calibration period $[\mathrm{m}]$ & 8460 & 2.0 & K-values \\
\hline $\mathrm{ME}_{\mathrm{Hmean}}:$ mean error of mean hydraulic head for a given well for the period $1990-2000[\mathrm{~m}]$ & 9198 & 1.0 & K-values \\
\hline $\mathrm{ME}_{\text {Layers_mean }}$ : mean hydraulic head error for each model layer $[\mathrm{m}]$ & 9198 & 1.0 & K-values \\
\hline
\end{tabular}

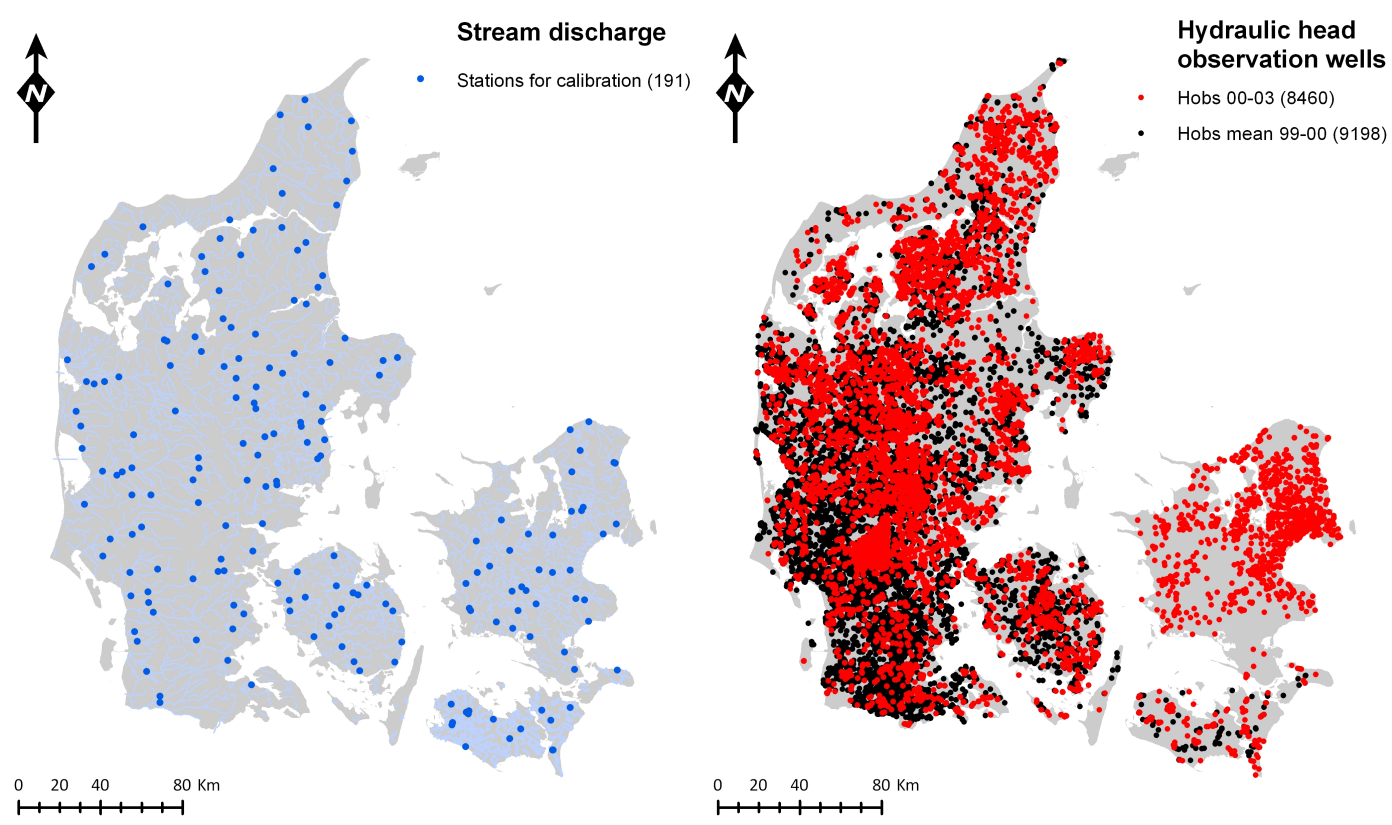

Fig. 5. All available discharge stations and observations wells for the calibration period 2000-2003.

of the different groups of observation wells, the ME of each model layer ( $\mathrm{ME}_{\text {layer }}$ and $\left.\mathrm{ME}_{\text {layermean }}\right)$ is added to the objective functions. This is done in order to have some control of the model performance in different geological units.

Although different objective functions are included in the optimisation, the models are still unconstrained with regard to important water balance components such as evapotranspiration. Problems related to missing constraint of other hydrological variables are not solved in the current study and will be difficult to address at the national scale. Instead, an attempt is made to evaluate the physical realism of the optimised parameter set and the seasonal dynamics of recharge at a national scale. The ongoing HOBE project (Jensen and Illangasekare, 2011) investigates the issues of unconstrained models in more detailed studies including a wider range of observation data types, including flux stations, soil moisture networks and remote sensing data (Stisen et al., 2011a).

Weighting of multiple objective functions will in most cases become a somewhat subjective discipline, especially when observations vary in unit, number and uncertainty. The weighting in the calibration of the National Water Resources Model is done based on an initial model run after which each observation is assigned a group-specific weight according to the relative weights in Table 3. This is necessary in order to guide the parameter optimisation in the desired direction while keeping the overall purpose of the model in mind. The weighting between discharge and head data is, following Table $3,60 \%$ on discharge and $40 \%$ on hydraulic heads. In a recent paper, Stisen et al. (2011b) evaluated different weighting schemes and initial parameter values for a sub-model 


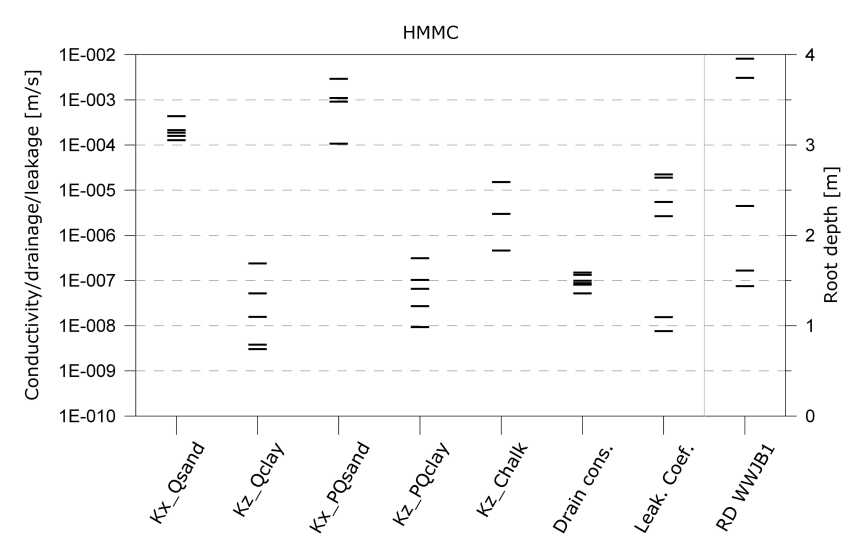

Fig. 6. Optimised parameter values for all model-domains with HMM precipitation correction.

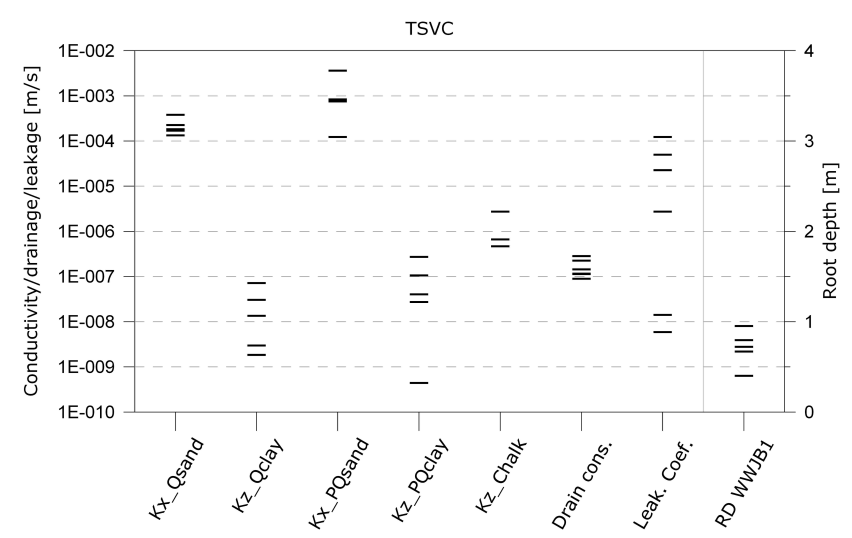

Fig. 7. Optimised parameter values for all model-domains with TSV precipitation correction.

of the National model and found limited sensitivity to intergroup weighting primarily because honouring both discharge and head data does not necessarily conflict on optimal parameters. Likewise, different physically realistic initial values resulted in similar optimised parameter sets.

\section{Results}

\subsection{Optimised parameters}

Before evaluating the model performance on the specific objective functions, the optimised parameter sets are evaluated. The optimised parameters across model domains are illustrated in Figs. 6 and 7 for the HMM and TSV correction methods, respectively. The resulting parameter values are quite similar for both methods and generally fall within the expected ranges in Table 2, except for the root depth for the model based on the HMM correction method. For the hydraulic conductivities and the leakage coefficient, some differences between model domains are observed. However, the main difference between the parameters when the two

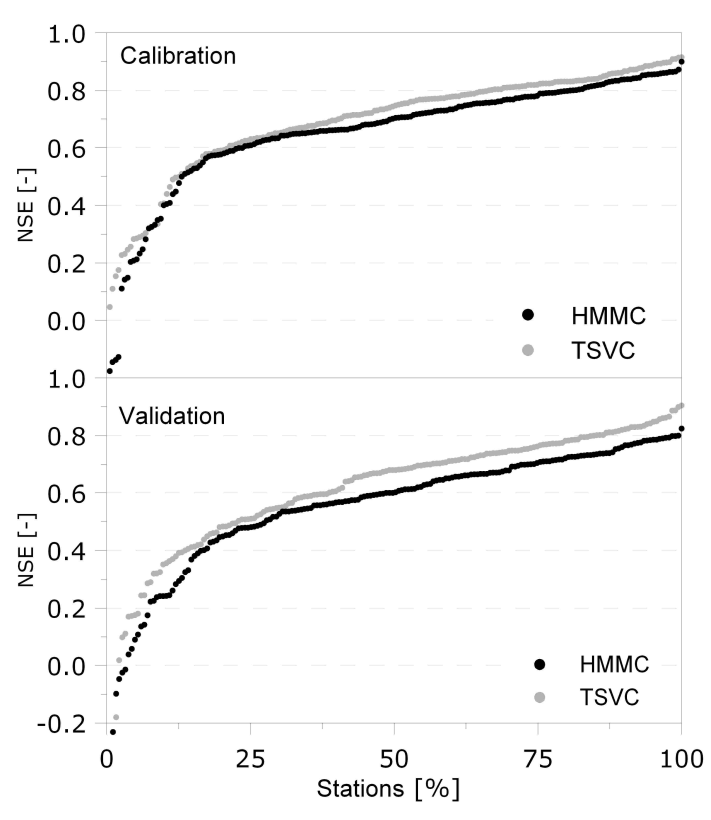

Fig. 8. Sorted model performance for NSE for both models during calibration and validation.

different correction methods are applied is on the root depth, where the HMM correction results in very large values in contrast to the TSV method, which results in values well within the expected ranges.

\subsection{Performance on objective functions}

The main model evaluation criteria are the objective functions utilized in the calibration. Among these, the NSE is the criteria most influenced by seasonal changes in the precipitation dynamics, as examined here through the comparison of two precipitation gauge catch correction methods. The NSE values for the HMM and TSV corrected models are illustrated in Fig. 8 for both the calibration and validation periods. The individual discharge stations (191 for calibration and 183 for validation) are sorted according to their performance, and the result shows a clear improvement in model performance when using the TSV correction method. This is especially the case for the validation period, although the validation results are generally worse than the calibration results. During calibration, $51 \%$ of the stations have NSE above 0.70 when HMM correction is used, compared to $71 \%$ of the stations using the TSV correction. For the validation period, these numbers drop to $28 \%$ and $46 \%$ for the HMM and TSV methods, respectively. It should be noted that the evaluation above focuses on the percentage of stations above or below certain performance criteria and not on average NSE values. This is due to the fact that several discharge stations underperform significantly, with NSE values below 0.5 . The reasons for poor model performance at specific stations has been investigated prior to model calibration, and in the process several stations have been disregarded whenever evidence 

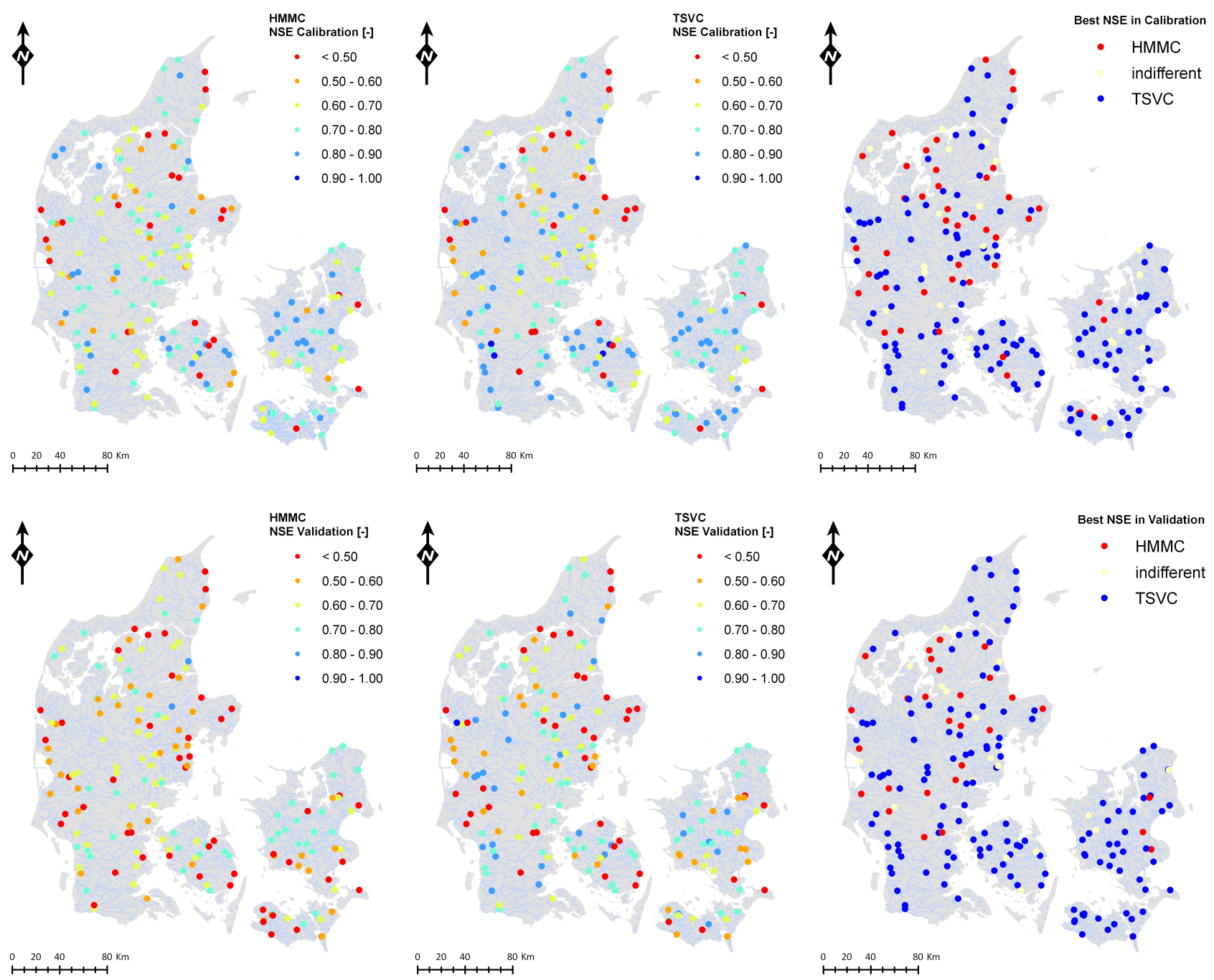

Fig. 9. Distributed map of model performance for NSE for both models during calibration and validation.

was found of structural disturbances of the natural flow, such as fish farms and weirs, but none have been removed due to poor initial performance only. The remaining stations which perform poorly represent smaller catchments $\left(<100 \mathrm{~km}^{2}\right)$ subject to higher sensitivity to model structural errors caused by the parsimonious parameterisation approach and geological model errors. Although these stations might impact the model optimisation, they are included equally in all optimisations and will have a similar impact across optimisations.

The maps in Fig. 9 illustrate the spatial distribution of the NSE across the national model domains, revealing a systematically better performance in the southern parts of the country, especially for the validation period where almost all stations perform better using the TSV correction.

Figure 10 shows a graph of the absolute WBE sorted according to performance. Also for the total water balance error, the TSV method yields better results, although only in the poorest performing $40-50 \%$ of the stations, whereas the best $40-50 \%$ perform similarly. For the HMM-corrected method, $86 \%$ of the stations have a WBE below $25 \%$ during calibration whereas that is the case for $92 \%$ of the stations when the models are calibrated on the basis of the TSV correction. During validation those numbers drop to $73 \%$ for the HMM-corrected model and $78 \%$ for the TSV corrected.

In order to get an overview of the total water balance errors, only the most downstream station in each catchment has been selected to avoid redundancies in cases where one catchment has several gauging stations. The WBE for the 126 downstream stations, covering approximately $55 \%$ of the total model area, are illustrated in Fig. 11. The maps indicate very similar performance on WBE for the two precipitation correction methods for both calibration and validation periods. Even though the TSV method performed better on WBE for the $50 \%$ worst performing stations (Fig. 10), this seems not to be reflected in the overall water balance error 


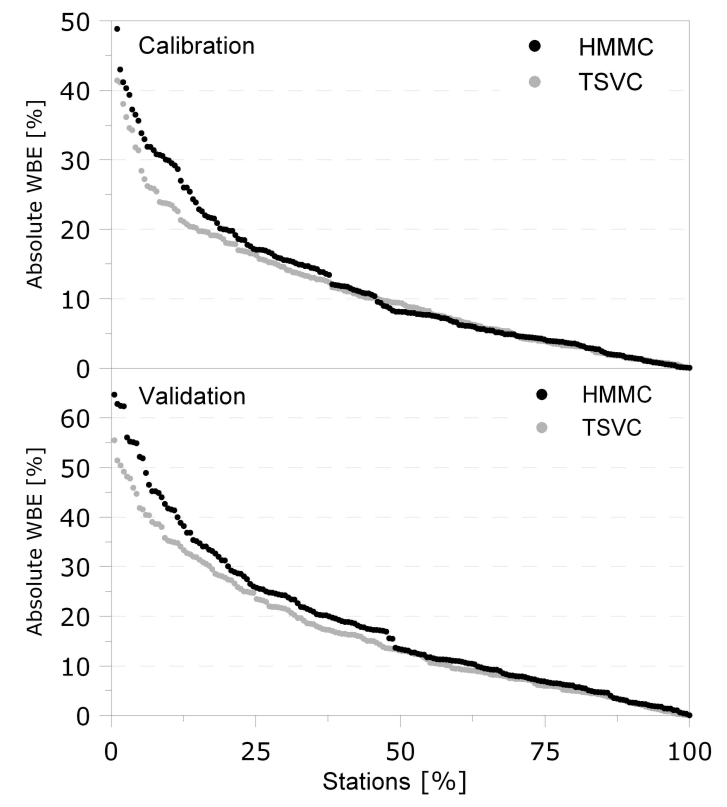

Fig. 10. Sorted model performance for absolute WBE for both models during calibration and validation.

because the large catchments generally perform well and outweigh the smaller catchments in the overall assessment.

The absolute water balance errors in the summer months $\left(\mathrm{WBE}_{\text {summer }}\right)$ are quite similar for both correction methods during both calibration and validation (Fig. 12), probably owing to the fact that the two precipitation inputs are almost identical for the summer months (Fig. 2) and that the summer discharge is largely groundwater feed.

The performances on hydraulic head levels, expressed through the RMSE for each computational model layer based on data from the calibration and validation periods, are shown in Fig. 13. This reveals a slight difference between the two correction methods in favour of the HMM correction, although both perform very similar.

\subsection{Alternative model evaluations}

\subsubsection{Proxy-basin test}

The proxy basin approach applied to model domain 2 provides an additional validation of the robustness of the two correction methods, since the model performance of model domain 2 will be highly dependant on the validity of the optimised parameter set for model domain 1. Figure 14 shows both NSE and absolute WBE for model domain 2 for the validation period (2004-2007). It is evident from the figure that stream flow dynamics and especially water balances are reproduced much better when the TSV correction method has been applied, giving a clear indication that the parameter set obtained using this input is more robust.

\subsubsection{Differential split sample test}

As illustrated in Fig. 4, the validation period has an average winter precipitation rate similar to the calibration period. However, the validation period covers a much wider range of wet and dry years. Especially the winters of 2005/2006 and 2006/2007 represent dry and wet winters, respectively. Therefore an additional validation test has been performed separately for two sub-periods, namely the hydrological years 2005/2006 and 2006/2007. This test can be thought of as a simple differential split sample test (Klemes, 1986; Seibert, 2003) where the model is calibrated to one particular climate condition and validated for both drier and wetter conditions. The differential split sample test, shown in Figs. 15 and 16, gives another clear indication of the superior performance of the TSV correction, since models based on this correction perform significantly better for both drier and wetter than for average conditions.

\subsubsection{Optimised parameters and recharge dynamics}

As expressed above, the large difference in optimised root depth is expected to be caused by the imbalance between summer and winter ET dynamics combined with a winter precipitation bias in the HMM-corrected precipitation. Whereas Figs. 6 and 7 gave the results of optimised root depth values for winter wheat on soil type JB1, Fig. 17 illustrates the effective summer maximum root depth for each model domain. Since the root depth varies according to vegetation and soil type (Table 1), the effective average root depth will depend on the fractions of land use and soil types within each domain. Figure 17 reveals an even larger difference between the models than Figs. 6 and 7, and a large spread between model domains for the HMM model. The differences in effective root depth has an impact on internal model variables such as the groundwater recharge. An example is seen in Fig. 18, where simulated average monthly groundwater recharge for all model grids is shown for the two correction methods. This illustration shows that the temporal patterns of recharge and groundwater uptake are quite different. Whereas the TSV based model has a smooth transition between winter and summer, the HMM based model displays a larger variation in the recharge dynamics.

\subsubsection{Separating the effect of long term bias and higher variability}

The differences between the HHM and the TSV correction methods are threefold. Since they are calculated for different time periods, there can be a systematic bias between corrections during the two periods, but in addition there is an improved spatio-temporal resolution of the TSV correction, which is calculated individually for each day and each $10 \mathrm{~km}$ grid. In order to investigate the relative importance of long term bias, a third precipitation correction was applied. This 

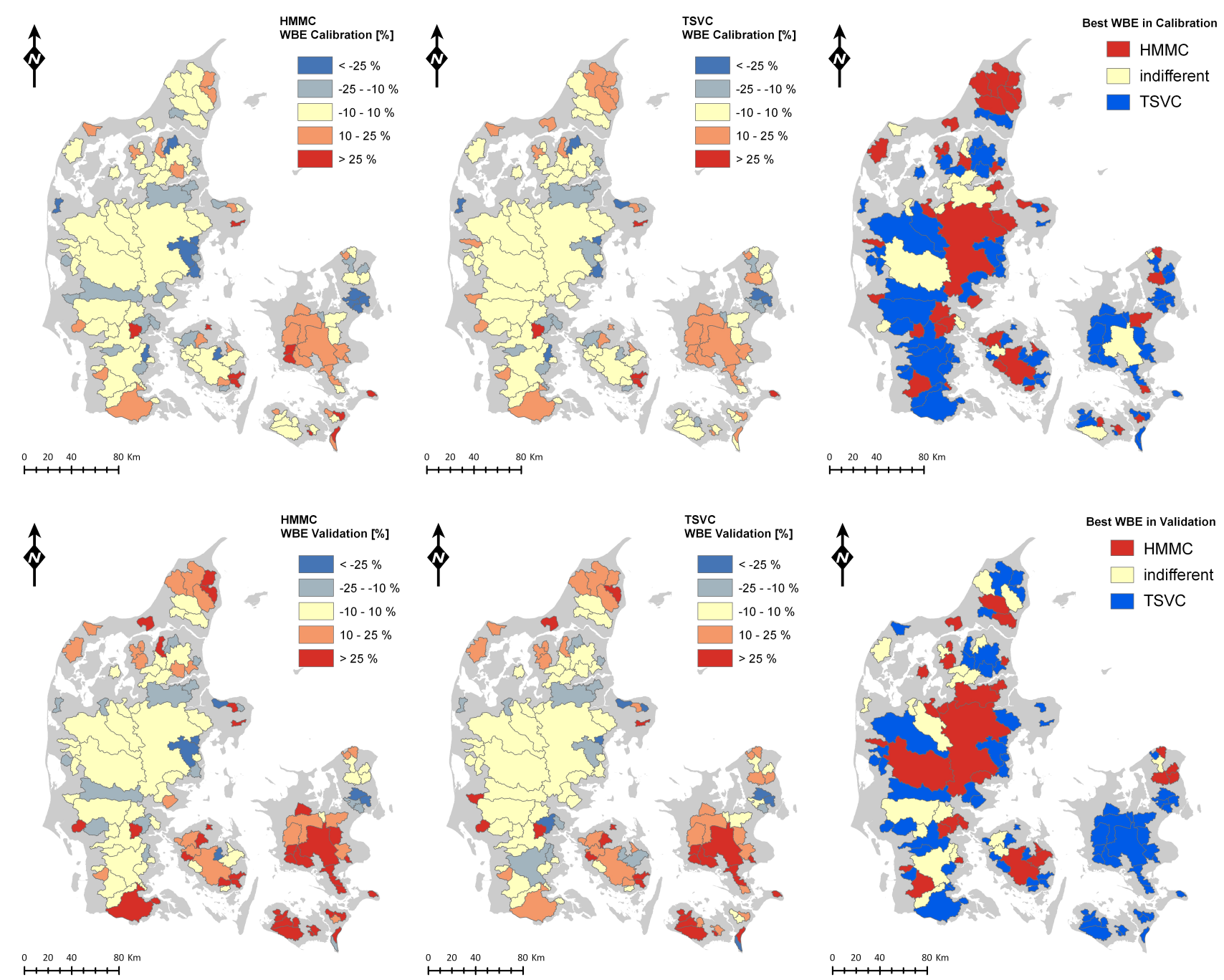

Fig. 11. Distributed map of model performance for WBE for both models during calibration and validation.

correction, named the current mean monthly (CMM) correction, is similar to the HMM correction since it is based on mean monthly factors for the entire country. However, the CMM correction is based on the TSV correction for the calibration/validation period 2000-2007. The CMM corrected precipitation data was used in the optimisation of two model domains (1 and 5) and the model performance for these models was compared to the same domains using the HMM and TSV corrections. The results are given in Fig. 19, which reveal that during calibration the CMM and TSV corrections yield quite similar results, which differ from the HMM correction-based model. During validation for the split sample years 2005/2006 and 2006/2007, results are more mixed. For the year 2006/2007, the CMM based model performs very similarly to the TSV based model, whereas for the year 2005/2006, results are more similar to the HMM based model.

\section{Discussion}

The reason for the large discrepancies between the optimised root depths of the HMM and TSV correction based models (Figs. 6 and 7) should, according to our interpretation, be found in the precipitation input, since all other input and parameters are similar. The HMM-corrected precipitation input has more winter precipitation than the TSV corrected, in the order of $10 \%$ (Fig. 1b). Combined with the very low reference ET values in Denmark during winter (Fig. 3), excess winter precipitation can only be lost through evapotranspiration during spring and summer. This forces the model to increase the root depth through calibration in order to increase spring and summer ET. For the TSV correction, it is assumed that a better representation of winter precipitation results in a more balanced model, where the optimal parameter values are within a physical plausible range. Apart from being physically unrealistic, the very large root depths of the 


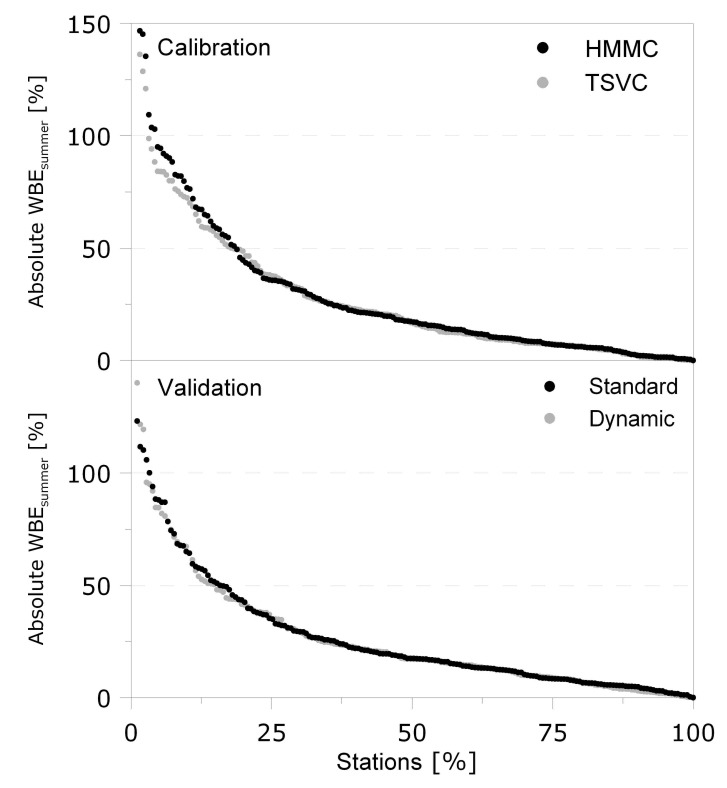

Fig. 12. Sorted model performance for absolute $\mathrm{WBE}_{\text {summer }}$ for both models during calibration and validation.

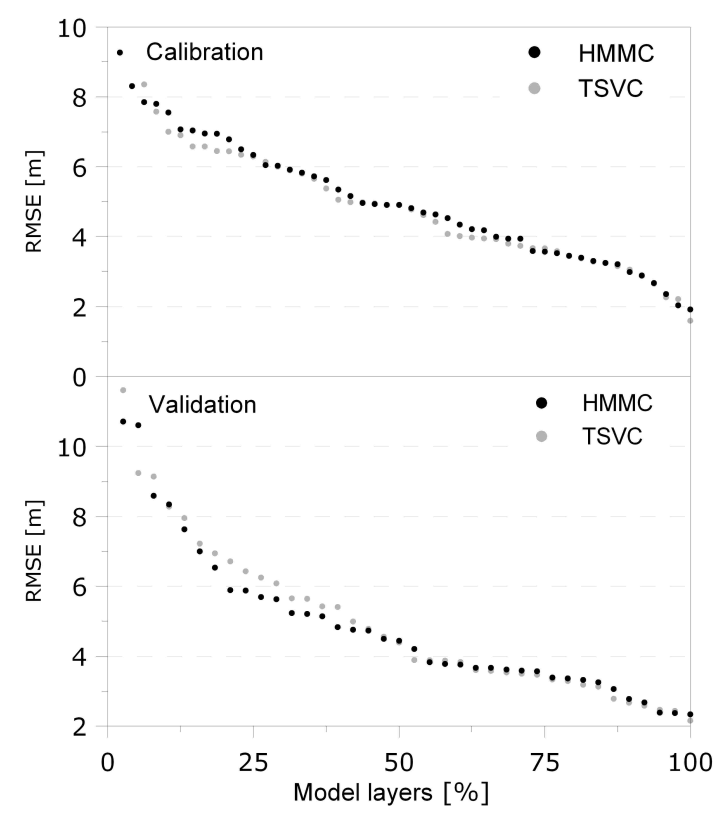

Fig. 13. Sorted model performance for RMSE of hydraulic head for both models during calibration and validation.

models based on the HMM correction of the precipitation have an effect on model variables not included in the objective functions. This is illustrated in Fig. 18, showing the seasonal patterns of the simulated groundwater recharge for the two correction methods. Whereas the TSV method shows a reasonable seasonal pattern comparable to the overall climate dynamics (Fig. 3), the HMM correction has an unexpected seasonal recharge pattern with a net uptake in April and May,

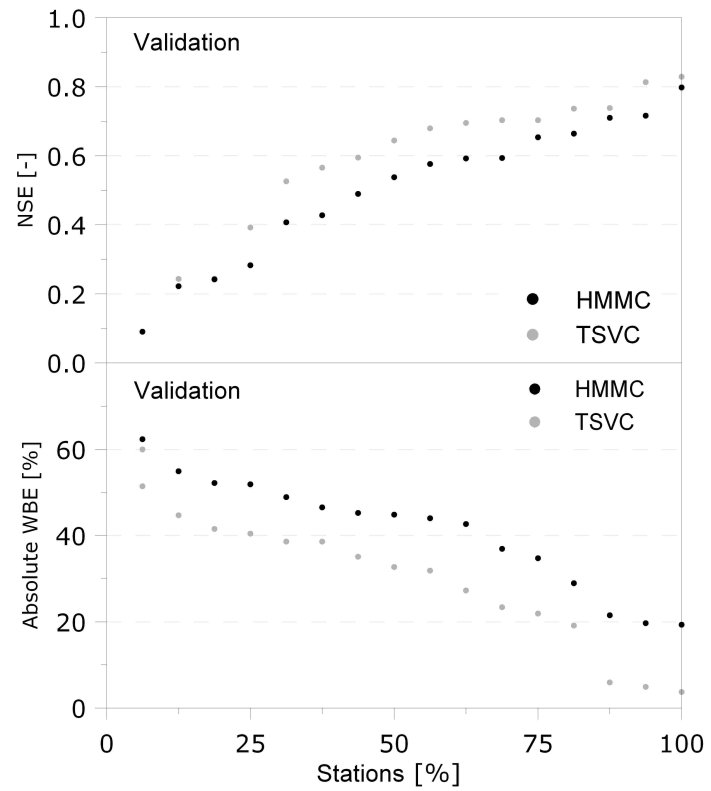

Fig. 14. Sorted model performance for NSE and absolute WBE both models for the proxy basin application to model domain 2 during the validation period.

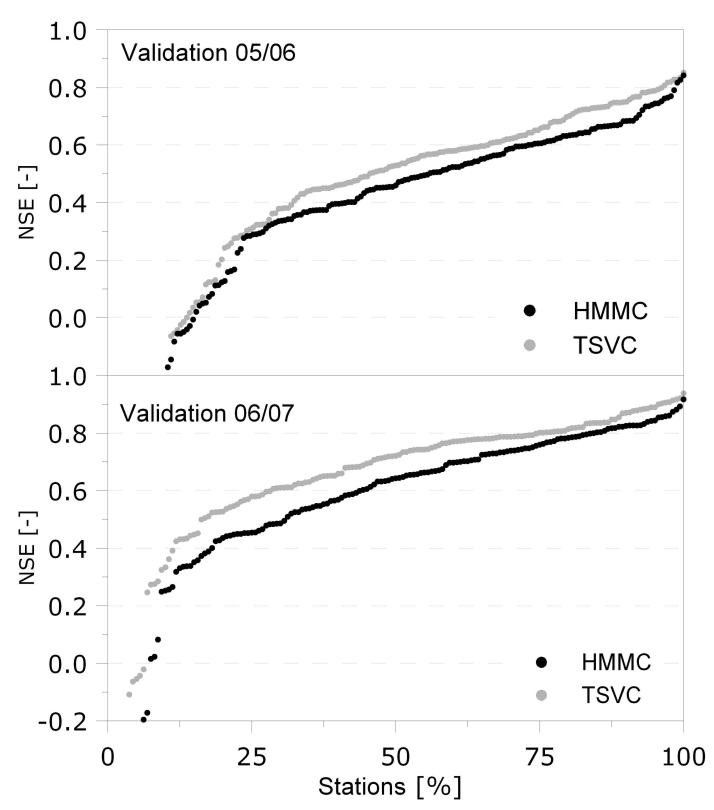

Fig. 15. Sorted model performance for NSE for both models during two additional validations periods (June 2005 and July 2006).

compensated by a large release in July. This pattern is caused by the unrealistically large root depth allowing the model to extract large volumes of water for transpiration during April and May, which is then replenished during July when the root depths for agricultural land are reduced. From a climate input point of view (Fig. 3), there is nothing in support of recharge rates being higher in July than in August and September. 


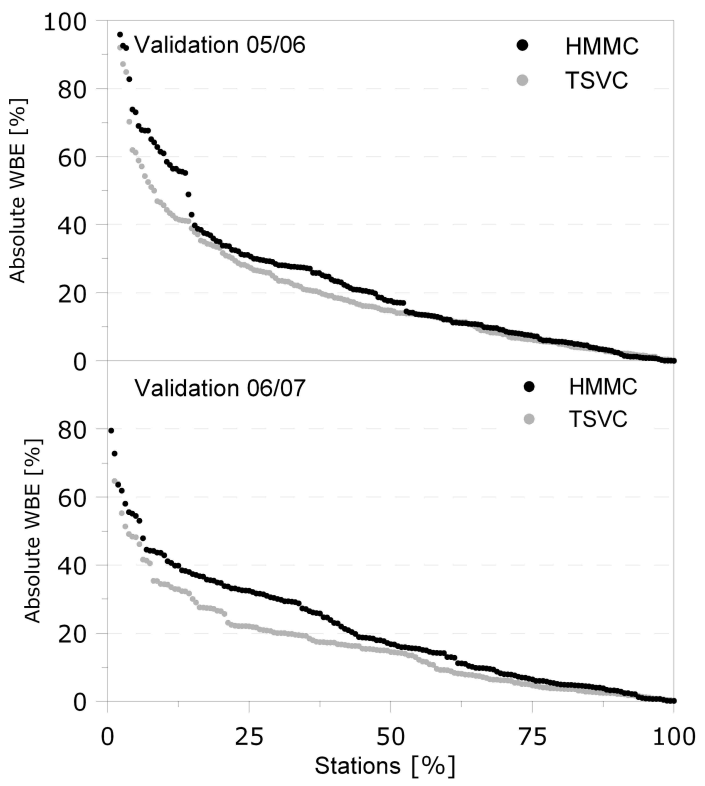

Fig. 16. Sorted model performance for absolute WBE for both models during two additional validation periods (June 2005 and July 2006).

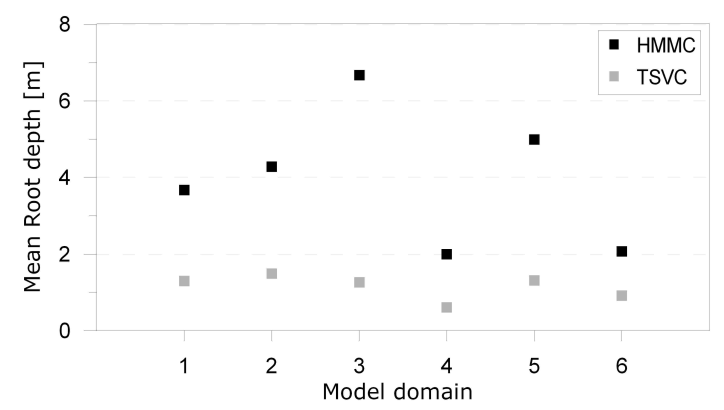

Fig. 17. Effective average summer root depths for the two optimised models for each mode domain.

For the hydraulic conductivities (Figs. 6 and 7), the difference in optimal parameter values for similar geological units is expected due to the spatial differences in geology. For the leakage coefficient, differences between model domains are also expected primarily due to scale issues attributed to the quite different topographical nature of the domains. In the outwash plains of Western Denmark, the terrain slopes are gentler than in Eastern Denmark where the terrain was formed by ice during the last glaciation. The difference in topography will have an effect on the surface watergroundwater interaction when represented by a model based on a $500 \mathrm{~m}$ grid.

The model performance results in the current study have demonstrated that a significantly better performance could be achieved on simulated stream discharge dynamics (NSE) when applying a TSV precipitation correction. Results on multi-annual water balances were also in favour of the TSV

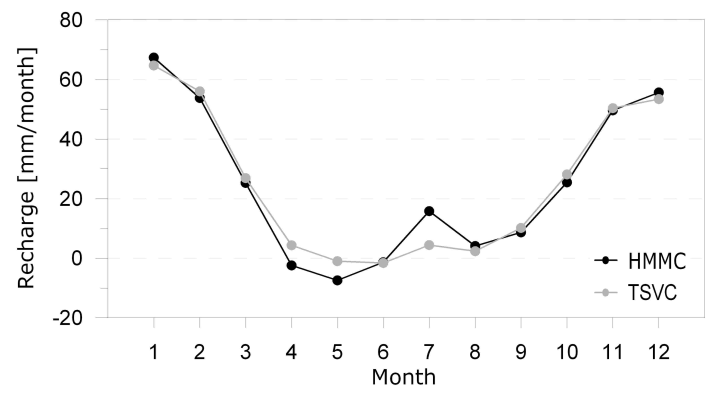

Fig. 18. Average monthly simulated groundwater recharge for all grids in the National model for the two optimised models.

correction although less conclusive, mainly due to the fact that models based on both correction methods can be calibrated to perform well for average conditions. In addition, the differential split sample test underlined these conclusions also when the models were evaluated for years with very different precipitation patterns. It is especially interesting that, whereas the WBE for the entire validation period did not deviate significantly between the two models, the TSV model clearly outperforms the HMM model for both dry and wet conditions separately. This again speaks in favour of the TSV model in terms of both dynamics of the precipitation input and the robustness of the optimised parameter set. Such tests are extremely valuable when hydrological models are calibrated for the current/historical climate and subsequently used to asses the impact on future climate conditions.

The general improvement of model performance achieved using the TSV corrected precipitation data can be attributed to three aspects of the precipitation correction methods: long term bias, temporal and spatial variability. The separate effect of the removal of the long term bias is evaluated (Fig. 19) and indicates that during calibration the removal of the systematic bias seems more important regarding model performance than the improved spatio-temporal resolution. This might seem surprising, although it should be kept in mind that the calibration period 2000-2004 has a strong tendency towards a systematic bias (Fig. 4), meaning that on a seasonal basis, the difference between the TSV and the CMM corrections are quite small. In addition, the discharge is largely groundwater controlled and therefore might respond at a timescale which is not affected greatly by the daily differences in correction factors. More interesting results are perhaps found when analysing the results for the two split sample validation years 2005/2006 and 2006/2007. As illustrated in Fig. 4, the year 2005/2006 has a TSV correction below the HMM correction, whereas the year 2006/2007 has higher corrections more comparable to the general bias in the calibration period; this is used to illustrate the impact of correction method for validation years with different biases. It is evident that when biases are systematic, the aggregated CMM correction will produce results quite similar to the TSV correction (Validation year 2006/2007), especially for NSE (Fig. 19b). 

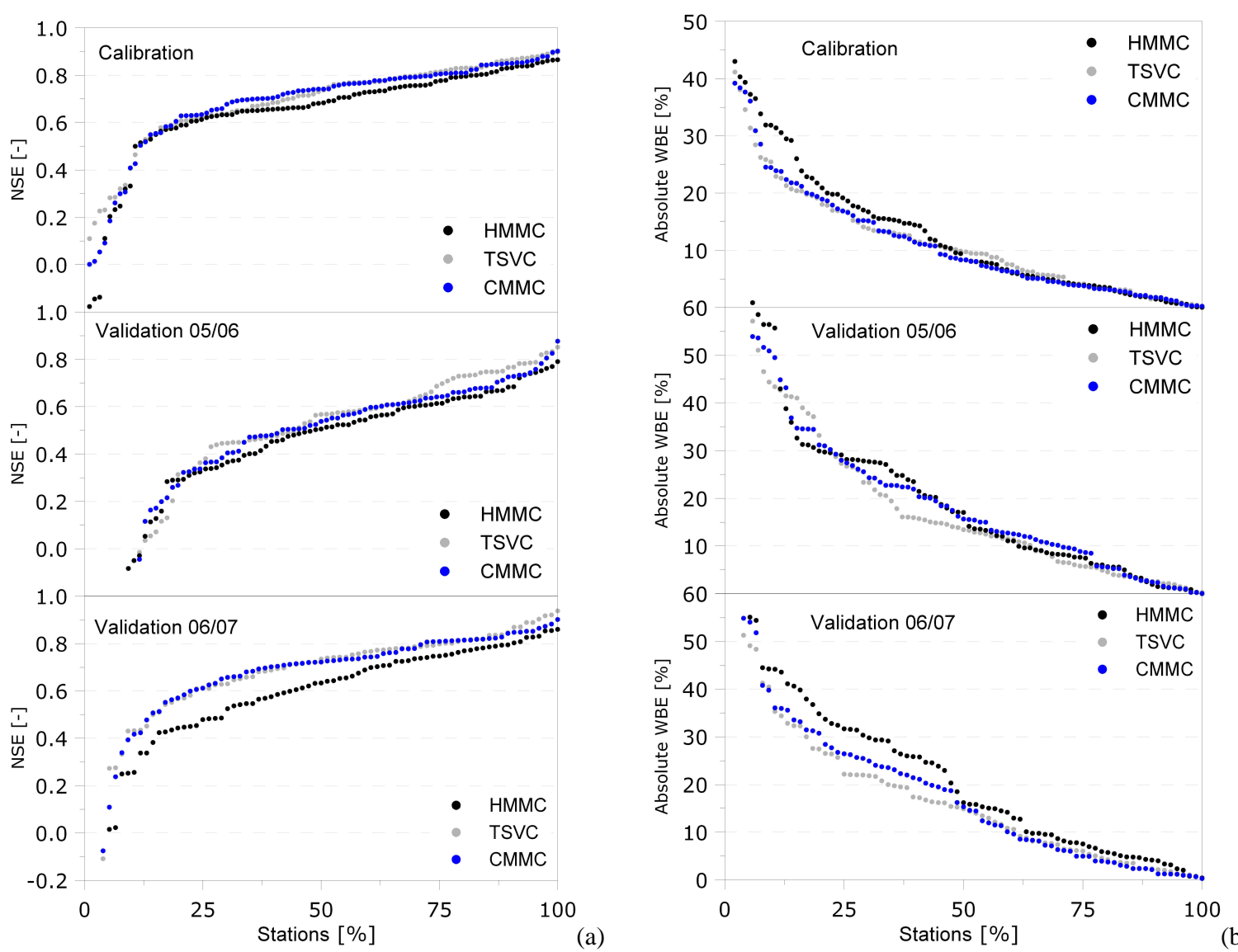

Fig. 19. Calibration and split sample validation results for discharge stations in model domains 1 and 5 including the current mean monthly (CMM) corrected precipitation data.

However, when biases are of alternating direction compared to the calibration period, such as for the year 2005/2006, the CMM correction yields results more similar to the HMM correction, indicating that there is an improvement by using the TSV correction. Unfortunately our data did not include shifting annual biases during the calibration period, which could have given other results in favour of the TSV correction compared to the CMM correction also for the calibration period.

Similar analyses in other regions, with a faster rainfallrunoff response, might have pointed to different conclusions. It is somewhat surprising that the spatial aspect seems to have limited effect on model performance when comparing a uniform correction to a spatially distributed one. However, the fact that each model domain is calibrated separately, and that spatial trends are mainly found on a scale larger than the model domain sizes, could explain this.

\section{Concluding remarks}

Appropriate precipitation gauge catch correction should be considered before undertaking detailed water balance studies, since even relatively small systematic biases in precipitation can have major implications on other hydrological fluxes such as evapotranspiration or recharge. In transitional climates with frequent variations in precipitation types, both from day-to-day and between years, dynamic precipitation gauge catch correction is particularly important. This is especially the case when transient hydrological model calibration is carried out, since optimal model parameters can vary considerably depending on seasonality and variability of precipitation input.

Our study highlights the importance of unbiased precipitation data, especially when rigorous optimisation is performed, because depending on the objective functions used, biases can be compensated for by tuning model parameters. As found in other studies (Oudin et al., 2006), the ability of parameter compensation to biases is problematic from a strictly scientific point of view because it highly limits the general validity of the models, while it can be regarded a blessing from an operational perspective. 
This can be extremely problematic when the hydrological model is subsequently used for climate change impact assessment, because the compensating effect of the tuned model parameters will not hold true under future and different climate conditions. Therefore differential split sample testing can give additional insight into the reliability of the model under different climate conditions. Our differential split sample test revealed a significantly better performance of the model based on TSV corrected precipitation for both drier and wetter than average years, demonstrating the superior robustness of the TSV correction.

Regarding optimised parameter values, calibration of models based on HMM corrected precipitation resulted in very unrealistic root depth values caused by the need to compensate for a winter precipitation bias. Although the groundwater recharge rates in Fig. 18 cannot be compared directly to observations, the differences in seasonal pattern between the two models add to the conclusion that the parameterization of the TSV model is favourable.

We believe the conclusions made here are general for mid to high latitudes, especially in coastal climates where precipitation corrections based on standard 30-year climatologies are not suitable for detailed water balance assessments.

Compared to the previous study at the catchment scale (Stisen et al., 2011b), this nationwide analysis has demonstrated that optimal model parameters and the differences in parameters caused by precipitation correction methods are very consistent across the six domains covering Denmark. Secondly, the model performance was improved for both NSE and WBE for all model domains. Finally, the analysis has shown that the improvements in performance is primarily attributed to the long term temporal (seasonal) bias removal and only secondly to the improved spatial and short term (daily) temporal improvements. The latter conclusion is probably limited to the groundwater controlled environment analyses here.

The interesting question remaining is whether appropriate precipitation gauge catch corrections are generally applied in hydrological modelling studies. Going through the literature, we have found very few examples where modellers are specific about the precipitation correction applied. This is somewhat disturbing since meteorological institutions traditionally always supply uncorrected precipitation data to users. Wagner (2009) conducted a recent survey and questionnaire among 24 research institutions across Europe regarding common practices on the correction of precipitation in forest hydrology. The survey revealed very limited consideration to detailed precipitation correction. Of the 24 institutions, 19 reported to do no precipitation correction; of the remaining nine, three did gap filling only and only one was specific about the applied method for catch correction.

Based on the current study, the Danish Meteorological Institute is currently preparing a new dynamically corrected gridded precipitation dataset based on spatial interpolation of precipitation gauges after individual time varying correction and accounting for local shelter conditions. This will have a major impact on future water resources management in Denmark, including estimates of nitrate and pesticide leaching, climate impact assessment and implementation of the EU Water Framework Directive.

Acknowledgements. The Danish Meteorological Institute (DMI) is acknowledged for providing climate data and Flemming Vejen and Claus kern-Hansen, DMI for contributing with knowledge on the assumptions behind the precipitation correction methods in Allerup et al. (1997). The Danish Nature Agency, Ministry of Environment and the Ministry of Climate and Energy have supported the study financially. Jens Asger Andersen, Dirk-Ingmar Müller Wohlfeil, Clea Schneider and Stefán Meulengracht Sørensen, the Danish Nature Agency and Christen Duus Børgesen and Gitte BlicherMathiesen, Aarhus University have contributed with constructive discussions during the study.

Edited by: P. Molnar

\section{References}

Abbott, M. B., Bathurst, J. C., Cunge, J. A., Oconnell, P. E., and Rasmussen, J.: An Introduction to the European Hydrological System - Systeme Hydrologique Europeen, She, 2. Structure of A Physically-Based, Distributed Modeling System, J. Hydrol., 87, 61-77, 1986.

Adam, J. C. and Lettenmaier, D. P.: Adjustment of global gridded precipitation for systematic bias, J. Geophys. Res., 108, 4257, doi:10.1029/2002JD002499, 2003.

Adam, J. C., Haddeland, I., Su, F., and Lettenmaier, D. P.: Simulation of reservoir influences on annual and seasonal streamflow changes for the Lena, Yenisei, and Ob' rivers, J. Geophys. Res.Atmos., 112, D24114, doi:10.1029/2007JD008525, 2007.

Allerup, P. and Madsen, H.: Accuracy of Point Precipitation Measurements, Nord. Hydrol., 11, 57-70, 1980.

Allerup, P., Madsen, H., and Vejen, F.: A comprehensive model for correcting point precipitation, Nord. Hydrol., 28, 1-20, 1997.

Allerup, P., Madsen, H., and Vejen, F.: Standard values for precipitation correction (1961-90), Technical report 98-10, Danish Meteorological Institute, Copenhagen, Denmark, 1998.

Allerup, P., Madsen, H., and Vejen, F.: Correction of precipitation based on off-site weather information, Atmos. Res., 53, 231-250, 2000.

Andreassian, V., Perrin, C., Michel, C., Usart-Sanchez, I., and Lavabre, J.: Impact of imperfect rainfall knowledge on the efficiency and the parameters of watershed models, J. Hydrol., 250, 206-223, 2001.

Bardossy, A. and Das, T.: Influence of rainfall observation network on model calibration and application, Hydrology and Earth System Sciences, 12, 77-89, 2008.

Berezovskaya, S., Yang, D. Q., and Kane, D. L.: Compatibility analysis of precipitation and runoff trends over the large Siberian watersheds, Geophys. Res. Lett., 31, ,L21502, doi:10.1029/2004GL021277, 2004.

Beven, K.: How far can we go in distributed hydrological modelling?, Hydrol. Earth Syst. Sci., 5, 1-12, doi:10.5194/hess-5-12001, 2001. 
Beven, K.: Towards integrated environmental models of everywhere: uncertainty, data and modelling as a learning process, Hydrol. Earth Syst. Sci., 11, 460-467, doi:10.5194/hess-11-4602007, 2007.

Børgesen, C. D. and Schaap, M. G.: Point and parameter pedotransfer functions for water retention predictions for Danish soils, Geoderma, 127, 154-167, 2005.

Bowling, L. C., Lettenmaier, D. P., Nijssen, B., Graham, L. P., Clark, D. B., El Maayar, M., Essery, R., Goers, S., Gusev, Y. M., Habets, F., van den Hurk, B., Jin, J. M., Kahan, D., Lohmann, D., Ma, X. Y., Mahanama, S., Mocko, D., Nasonova, O., Niu, G. Y., Samuelsson, P., Shmakin, A. B., Takata, K., Verseghy, D., Viterbo, P., Xia, Y. L., Xue, Y. K., and Yang, Z. L.: Simulation of high-latitude hydrological processes in the Torne-Kalix basin: PILPS phase 2(e) - 1: Experiment description and summary intercomparisons, Global Planet. Change, 38, 1-30, 2003.

Detlefsen, N. and Plauborg, F.: Reevaluation of methods for calculating reference evapotranspiration - potential evapotranspiration, The Danish Institute of Agricultural Sciences, Foulum, Denmark, 2001.

Doherty, J.: PEST: Model-independent Parameter Estimation, Watermark Numerical Computing, Brisbane, 2004.

Fekete, B. M., Vorosmarty, C. J., Roads, J. O., and Willmott, C. J.: Uncertainties in precipitation and their impacts on runoff estimates, J. Climate, 17, 294-304, 2004.

Forland, E. J. and Hanssen-Bauer, I.: Increased precipitation in the Norwegian Arctic: True or false?, Climatic Change, 46, 485-509, 2000

Fortin, V., Therrien, C., and Anctil, F.: Correcting wind-induced bias in solid precipitation measurements in case of limited and uncertain data, Hydrol. Process., 22, 3393-3402, 2008.

Goodison, B. E., Louie, P. Y. T., and Yang, D.: WMO solid precipitation measurement intercomparison, WMO/TD 872, World Meteorological Organization, Geneva, 1998.

Gourley, J. J. and Vieux, B. E.: A method for evaluating the accuracy of quantitative precipitation estimates from a hydrologic modeling perspective, J. Hydrometeorol., 6, 115-133, 2005.

Graham, D. N. and Butts, M. B.: Flexible, integrated watershed modelling with MIKE SHE, in: Watershed Models, edited by: Singh, V. P. and Frevert, D. K., Taylor and Francis, Boca Raton, Fla., 245-272, 2005

Greve, M. H., Greve, M. B., Bocher, P. K., Balstrom, T., BreuningMadsen, H., and Krogh, L.: Generating a Danish raster-based topsoil property map combining choropleth maps and point information, Geografisk Tidsskrift-Danish, J. Geogr., 107, 1-12, 2007

Groisman, P. Y. and Legates, D. R.: Documenting and detecting long-term precipitation trends: Where we are and what should be done, Climatic Change, 31, 601-622, 1995.

Henriksen, H. J., Troldborg, L., Nyegaard, P., Sonnenborg, T. O., Refsgaard, J. C., and Madsen, B.: Methodology for construction, calibration and validation of a national hydrological model for Denmark, J. Hydrol., 280, 52-71, 2003.

Henriksen, H. J., Troldborg, L., Højberg, A. L., and Refsgaard, J. C.: Assessment of exploitable groundwater resources of Denmark by use of ensemble resource indicators and a numerical groundwater-surface water model, J. Hydrol., 348, 224-240, 2008 .
Højberg, A. L., Troldborg, L., Stisen, S., Christensen, B. S. B., and Henriksen, H. J.: Stakeholder driven update and improvement of a national water resources model, Environ. Model. Softw., doi:10.1016/j.envsoft.2012.09.010, in press, 2012.

Huffman, G. J., Adler, R. F., Arkin, P., Chang, A., Ferraro, R., Gruber, A., Janowiak, J., McNab, A., Rudolf, B., and Schneider, U.: The Global Precipitation Climatology Project (GPCP) Combined Precipitation Dataset, B. Am. Meteorol. Soc., 78, 5-20, 1997.

Jensen, K. H. and Illangasekare, T. H.: HOBE: A Hydrological Observatory, Vadose Zone J., 10, 1-7, 2011.

Kampf, S. K. and Burges, S. J.: Quantifying the water balance in a planar hillslope plot: Effects of measurement errors on flow prediction, J. Hydrol., 380, 191-202, 2010.

Kavetski, D., Kuczera, G., and Franks, S. W.: Bayesian analysis of input uncertainty in hydrological modeling: 2. Application, Water Resour. Res., 42, W03408, doi:10.1029/2005WR004376, 2006.

Keating, E. H., Vesselinov, V. V., Kwicklis, E., and Lu, Z. M.: Coupling basin- and site-scale inverse models of the Espanola aquifer, Ground Water, 41, 200-211, 2003.

Klemes, V.: Operational Testing of Hydrological SimulationModels, Hydrolog. Sci. J. - Journal des Sciences Hydrologiques, 31, 13-24, 1986.

Kollet, S. J. and Maxwell, R. M.: Integrated surface-groundwater flow modeling: A free-surface overland flow boundary condition in a parallel groundwater flow model, Adv. Water Resour., 29, 945-958, 2006.

Kristensen, K. J. and Jensen, S. E.: A model for estimation the actual evapotranspiration from the potential one, Nord. Hydrol., 6 , 170-188, 1975.

Larson, L. W. and Peck, E. L.: Accuracy of Precipitation Measurements for Hydrologic Modeling, Water Resour. Res., 10, 857863, 1974.

Legates, D. R.: Global and Terrestrial Precipitation - A Comparative-Assessment of Existing Climatologies, Int. J. Climatol., 15, 237-258, 1995.

Leimer, S., Pohlert, T., Pfahl, S., and Wilcke, W.: Towards a new generation of high-resolution meteorological input data for small-scale hydrologic modeling, J. Hydrol., 402, 317-332, 2011.

Looper, J. P., Vieux, B. E., and Moreno, M. A.: Assessing the impacts of precipitation bias on distributed hydrologic model calibration and prediction accuracy, J. Hydrol., 418, 110-122, 2012.

McMillan, H., Jackson, B., Clark, M., Kavetski, D., and Woods, R.: Rainfall uncertainty in hydrological modelling: An evaluation of multiplicative error models, J. Hydrol., 400, 83-94, 2011.

Mizukami, N. and Smith, M. B.: Analysis of inconsistencies in multi-year gridded quantitative precipitation estimate over complex terrain and its impact on hydrologic modeling, J. Hydrol., 428, 129-141, 2012.

Nash, I. E. and Sutcliffe, I. V.: River flow forecasting through conceptual models, J. Hydrol., 10, 282-290, 1970.

Nespor, V. and Sevruk, B.: Estimation of wind-induced error of rainfall gauge measurements using a numerical simulation, J. Atmos. Ocean. Tech., 16, 450-464, 1999.

Oudin, L., Perrin, C., Mathevet, T., Andreassian, V., and Michel, C. Impact of biased and randomly corrupted inputs on the efficiency and the parameters of watershed models, J. Hydrol., 320, 62-83, 2006. 
Plauborg, F., Refsgaard, J. C., Henriksen, H. J., Blicher-Mathiasen, G., and Kern-Hansen, C.: Water balance at field and catchment scale, The Danish Institute of Agricultural Sciences, Foulum, Denmark, 2002.

Refsgaard, J. C.: Parameterisation, calibration and validation of distributed hydrological models, J. Hydrol., 198, 69-97, 1997.

Refsgaard, J. C.: Towards a formal approach to calibration and validation of models using spatial data, in: Spatial patterns in catchment hydrology: observations and modelling, edited by: Grayson, R. B. and Blöschl, G., Cambridge University Press, 329-354, 2000.

Refsgaard, J. C., Stisen, S., Højberg, A. L., Olsen, M., Henriksen, H. J., Børgesen, C. D., Vejen, F., Kern-Hansen, C., and BlicherMathiasen, G.: Water balance in Denmark - Guide to quantification of water balances based on hydrological data for the period 1990-2010), Report 2011/77, GEUS, Copenhagen, Denmark, 2011.

Scharling, M.: CLIMATEGRID - DENMARK, Precipitation $10 * 10$ km, Technical Report 98-17, Danish Meteorological Institute, Copenhagen, Denmark, 1998.

Scharling, M.: CLIMATEGRID - DENMARK, Precipitation, air temperature and potential evapotranspiration $20 * 20 \& 40 * 40 \mathrm{~km}$, Technical Report 99-12, Danish Meteorological Institute, Copenhagen, Denmark, 1999.

Seibert, J.: Reliability of model predictions outside calibration conditions, Nord. Hydrol., 34, 477-492, 2003.

Sevruk, B. and Nespor, V.: Empirical and theoretical assessment of the wind induced error of rain measurement, Water Sci. Technol., 37, 171-178, 1998.

Stisen, S., McCabe, M. F., Refsgaard, C. J., Lerer, S., and Butts, M.: Model parameter analysis using remotely sensed pattern information in a multi-constraint framework, J. Hydrol., 409, 337349, 2011a.
Stisen, S., Sonnenborg, T. O., Hojberg, A. L., Troldborg, L., and Refsgaard, J. C.: Evaluation of Climate Input Biases and Water Balance Issues Using a Coupled Surface-Subsurface Model, Vadose Zone J., 10, 37-53, 2011 b.

Therrien, R., McLaren, R. G., Sudicky, E. A., and Panday, S.: HydroGeoSphere: A three-domentional numerical model describing fully-integrated subsurface and surface flow and solute transport,Groundwater Simulations Group, University of Waterloo, Waterloo, Ontario, Canada, 2005.

Tian, X. J., Dai, A., Yang, D. Q., and Xie, Z. H.: Effects of precipitation-bias corrections on surface hydrology over northern latitudes, J. Geophys. Res.-Atmos., 112, D14101, doi:10.1029/2007JD008420, 2007.

Valéry, A., Andreassian, V., and Perrin, C.: Inverting the hydrological cycle: when streamflow measurements help assess altitudinal precipitation gradients in mountain areas, IAHS Publ., 333, 281285, 2009.

Vejen, F.: Pilotproject: Calculation of dynamic correction on Sams $\varnothing$, 1989-2003,Technical report 05-16, Danish Meteorological Institute, Copenhagen, Denmark, 2005.

Voisin, N., Wood, A. W., and Lettenmaier, D. P.: Evaluation of precipitation products for global hydrological prediction, J. Hydrometeorol., 9, 388-407, 2008.

Wagner, A.: Literature Study on the Correction of Precipitation Measurements, FutMon C1-Met-29(BY), Bavarian State Institute of Forestry, Freising, Germany, 2009.

Yan, J. S. and Smith, K. R.: Simulation of Integrated Surface-Water and Ground-Water Systems - Model Formulation, Water Resour. Bull., 30, 879-890, 1994.

Yang, D. Q., Kane, D., Zhang, Z. P., Legates, D., and Goodison, B.: Bias corrections of long-term (1973-2004) daily precipitation data over the northern regions, Geophys. Res. Lett., 32, L19501, doi:10.1029/2005GL024057, 2005. 